\title{
Occupational Recognition and Immigrant Labor Market Outcomes
}

\author{
Herbert Brücker \\ Humboldt University, BIM and \\ Institute for Employment Research (IAB)
}

Adrian Lerche

Institute for Employment Research (IAB)

\author{
Albrecht Glitz \\ Universitat Pompeu Fabra, IPEG \\ and Barcelona GSE
}

Agnese Romiti

University of Strathclyde - Glasgow

June 2020

\begin{abstract}
We analyze how the formal recognition of foreign qualifications affects immigrants' labor market outcomes. The empirical analysis is based on a novel German data set that links respondents' survey information to their administrative records, allowing us to observe immigrants at monthly intervals before, during and after their application for occupational recognition. We find that three years after obtaining recognition, immigrants earn 19.8 percent higher wages and are 24.5 percentage points more likely to be employed than immigrants in the control group. We further document that occupational recognition leads to full convergence of immigrants' earnings to those of their native counterparts.
\end{abstract}

We thank Gianluca Orefice, Imran Rasul and Uta Schönberg as well as numerous seminar participants for helpful comments on earlier drafts of the paper. Herbert Brücker gratefully acknowledges support by the German Research Foundation (DFG) in the priority program SPP 1764 "The German Labor Market in a Globalized World". Albrecht Glitz gratefully acknowledges financial support from the Spanish Ministerio de Economía y Competitividad (through the Severo Ochoa Programme for Centres of Excellence in R\&D (SEV-2015-0563) and Project No. ECO2014-52238-R) and the Spanish Ministerio de Ciencia, Innovación y Universidades (Project No. ECO2017-83668-R (AEI/FEDER, UE) and Ramón y Cajal Grant RYC-2015-18806). He also thanks the German Research Foundation (DFG) for funding his Heisenberg Fellowship (GL 811/1-1) and Alexandra Spitz-Oener for hosting him at Humboldt University Berlin from October 2014 to December 2016. Contact details: Herbert Brücker: herbert.bruecker@iab.de, Albrecht Glitz: albrecht.glitz@upf.edu, Adrian Lerche: adrian.lerche@iab.de, Agnese Romiti: agnese.romiti@strath.ac.uk. 


\section{Introduction}

It is well documented that in most developed economies immigrants have significantly worse labor market outcomes than their native counterparts (e.g. Dustmann and Frattini, 2013). Often, this appears to be due to a lack of human capital, which pushes immigrants into low paying and precarious jobs and excludes them from more desirable segments of the labor market. However, even immigrants with valuable skills acquired in their home country may have problems applying those skills in the host country, partly because of insufficient language proficiency (Chiswick and Miller, 2003), partly because of native employers' limited ability to assess immigrants' skills. Moreover, occupational licensing rules often prohibit immigrants from working in certain occupations. Such rules are increasingly widespread in immigrant-receiving countries (Sweetman et al., 2015). For instance, 25 percent of US and 22 percent of EU workers held an occupational license in 2015 (Kleiner, 2017; Koumenta and Pagliero, 2017).

While occupational regulation is meant to ensure minimum quality standards in a profession (Bryson and Kleiner, 2010), it probably has a particularly detrimental effect on immigrants' labor market outcomes. Immigrants whose credentials are not formally recognized typically cannot work in licensed occupations or credibly signal their skills to native employers who are often unfamiliar with foreign qualifications. The market may therefore underutilize immigrants' skills, consistent with the frequent occupational downgrading of immigrants after their arrival (see e.g. Friedberg, 2001, Mattoo et al., 2008, or Dustmann et al., 2013). Facilitating the recognition of foreign qualifications might overcome this inefficiency and fundamentally improve the economic integration of immigrants.

In this paper, we estimate the impact of occupational recognition - the formal certification of the equivalence between a foreign and native qualification - on immigrants' labor market outcomes. Our empirical analysis relies on a novel German data set that links detailed survey information on the timing of the application process with comprehensive social security records on the respondents' work histories in Germany. We estimate both static and dynamic difference-in-differences specifications, comparing outcomes of immigrants who obtain full recognition with those of immigrants who either never apply or are still in the process of applying. Theoretically, occupational recognition can improve labor market outcomes through two main mechanisms. First, a successful recognition gives immigrants access to labor market segments they could previously not enter. This not only increases their employment opportunities but also raises their earnings potential since regulated segments are often characterized by elevated wages, both because of higher returns to skills and because of monopoly rents from occupational licensing (e.g. Kleiner and Krueger, 2013; Gittleman et al., 2018). Second, occupational recognition reduces uncertainty about immigrants' skills which allows employers to better screen in 
the hiring process, leading to better matches between workers and firms.

Our empirical results show substantial positive effects of occupational recognition on wages and employment. Three years after obtaining full recognition, immigrants earn 19.8 percent higher wages and are 24.5 percentage points more likely to be employed than comparable immigrants in the control group. The employment effects are primarily driven by successful immigrants moving into occupations that were previously not accessible because of licensing restrictions. Our dynamic specification reveals that the employment probability increases rapidly with the receipt of occupational recognition whereas the wage gains only materialize with some delay. While our estimated impacts are most likely not representative for the average eligible immigrant due to positive selection on expected gains, they are relevant policy parameters in a setting where recognition options are offered on a more restricted scale and where selection into the recognition process is an inherent feature of the institutional setup.

Distinguishing between immigrant subgroups, we find that occupational recognition is particularly beneficial for foreign doctoral degree holders as well as physicians, dentists, veterinarians and pharmacists for whom recognition is mandatory to practice their profession. Occupational recognition, however, also improves the outcomes of workers who do not face mandatory recognition requirements, indicating that the formal certification of foreign qualifications has an independent value in the German labor market. We conclude by showing that immigrants' earnings grow significantly faster after obtaining recognition and eventually fully converge to those of their native counterparts. This could be interpreted as evidence for a similar quality of the work provided.

There is an extensive literature on occupational regulation and its interplay with foreign qualification recognition (Sweetman et al., 2015), with several studies documenting significant wage gains for immigrants from working in a regulated occupation (e.g. Gomez et al., 2015, or Tani, 2018). However, direct evidence on how the actual recognition of foreign credentials affects immigrants' labor market outcomes is limited. Kugler and Sauer (2005) exploit the fact that Soviet-trained physicians arriving in Israel in the early 1990s were exogenously assigned to different retraining tracks that differentially affected their probability of obtaining a medical license. The instrumental variable estimates show large returns from such a license of around 200 percent within 3 to 4 years after arrival. The IV-based approach in this study partly addresses the issue of selection on expected gains and identifies a local average treatment effect that is arguably more representative for the group of physicians at large. However, contrary to the present paper, the analysis is restricted to a single occupation. Chapman and Iredale (1993) provide related evidence by showing that immigrant men who unsuccessfully apply for recognition in Australia earn 15 to 30 percent lower wages than their successful counterparts. Tani (2017) documents that the official assessment of immigrants' foreign educational degrees after arrival in Australia is associated with significantly higher wages. We complement 
this existing literature by providing new evidence for Germany. While some of the qualitative results are similar, our analysis provides several innovations. First, we analyze the effects of occupational recognition for a broader set of both vocational and educational qualifications. Second, apart from wages, we also consider employment and occupational mobility as distinct outcomes in our empirical analysis. Third, we exploit detailed information about the precise timing of the recognition process to estimate dynamic effects at monthly frequency, allowing us to identify both short- and long-run effects of occupational recognition.

\section{Institutional Setting}

For an immigrant in the German labor market, the distinction between regulated and unregulated occupations is of central importance. Only individuals with the required professional qualifications or, in the case of immigrants, formal recognition of their foreign qualifications, are entitled to work in regulated occupations and use the corresponding job titles. ${ }^{1}$ The regulated segment of the German labor market comprises more than 400 occupations and makes up around 12.3 percent of total employment (own calculations based on Vicari, 2014), 38 percent of which are accounted for by the health sector (e.g. physicians, pharmacists and nurses), 28 percent by the public sector (e.g. policemen, teachers and social workers) and 25 percent by the technical sector (e.g. architects, engineers and physicists). Given this broad range of occupations, there are many different authorities in charge of the recognition process for regulated occupations, including various governmental authorities and professional chambers operating at the national, state or municipal level.

Contrary to regulated occupations, formal recognition is not a requirement for working in unregulated occupations. For most of these occupations, however, immigrants can still apply for an official assessment of their foreign qualifications which, if successful, can serve as a legally secure document confirming their equivalence with the German reference qualifications. Examples of such unregulated occupations are so-called training occupations (e.g. office management clerks, mechanics and electricians) and advanced training occupations (e.g. master craftsman qualifications, certified advisors and specialist commercial clerks). The main authorities responsible for the recognition of foreign qualifications in unregulated occupations are the chambers of industry and commerce (Industrie- und Handelskammern) and the regionally organized chambers of crafts

\footnotetext{
${ }^{1}$ In practice, occupational regulation can take many different forms with the literature mainly distinguishing between registration, certification and licensure. While there are no uniform definitions of these types of regulation, only licensure is generally viewed as being exclusionary in that it restricts access to certain occupations (see e.g. Kleiner and Krueger, 2013 or Sweetman et al., 2015). In distinguishing between regulated and unregulated occupations, we follow the German terminology which uses the terms regulated occupation and licensed occupation synonymously.
} 
(Handwerkskammern).

To apply for recognition, immigrants are not required to have German citizenship or a residence permit for Germany. In fact, immigrants are allowed to initiate the application process while still living abroad. ${ }^{2}$ Applications for occupational recognition need to be accompanied by extensive documentation, including a proof of identity, a tabular summary of the training courses completed, proofs of vocational qualification and relevant occupational experience, and evidence of other qualifications (e.g. continuing vocational training courses). All documents must be submitted in German, with the relevant translations made by publicly authorized or certified interpreters or translators. Applications are subject to an administrative fee ranging between 100 and 600 euros depending on the occupation and the federal state in which the application is submitted. The costs of fees and other expenses, for instance for translations and certifications of documents, must be borne by the applicants. Since 2005, a proof of language proficiency can be made an additional requirement, which applies for example to the case of physicians.

These features of the application process suggest that the bureaucratic hurdles to obtain occupational recognition in Germany are not negligible. According to our survey data, of those immigrants who hold a foreign certificate and could therefore apply for occupational recognition, only 35.8 percent do so. The main reasons put forward for not applying are that a recognition is not considered important (38.1 percent), that an application would have no chance of succeeding (12.9 percent), that the respondent does not know how to apply (6.6 percent), and that the procedure is too bureaucratic or timeconsuming (6.6 percent). Monetary costs, in contrast, are viewed as only a minor obstacle to applying (2.8 percent).

At the end of the recognition process, there are three possible outcomes: denial, partial recognition and full recognition. In case of partial recognition, the assessment notification describes the knowledge that is still missing and provides concrete suggestions for training or apprenticeship measures which, if completed successfully, can then lead to a new application. A decision of full recognition, in turn, certifies the equivalence of the foreign qualification with the relevant German reference qualification and gives the worker full access to the corresponding occupation and job title.

During most of our sample period, the recognition of European professional and vocational qualifications was regulated at the European level (EU Directive 2005/36/EC). In contrast, for immigrants from countries other than those of the European Economic Area and Switzerland, there was no common procedure regulating the recognition of foreign qualifications. Without a legal basis, decisions on the equivalence between foreign and German qualifications for these immigrants were more idiosyncratic, with the

\footnotetext{
${ }^{2}$ In our main estimation sample, we include immigrants who applied for recognition before their arrival in Germany (they make up 15 percent of all immigrants who eventually obtain full recognition). Excluding those individuals from the sample leaves our estimates virtually unchanged.
} 
applicant's country of origin often playing a decisive role for the application outcome. This unsatisfactory situation largely motivated the introduction of the Federal Recognition Act (Anerkennungsgesetz) in April 2012 whose aim was to simplify, standardize and accelerate the procedure for the recognition of foreign qualifications, and open up such procedures to groups not covered by previous legislation. However, 80 percent of immigrants in our sample applied for recognition before April 2012, so that our estimates largely reflect observations under the old legislative regime.

\section{Empirical Framework}

The administrative component of our data allows us to continuously track immigrants after their arrival in Germany. From the survey component, we also know if and when they receive occupational recognition. We use this information to compare the labor market outcomes of individuals after successful recognition with those of individuals who have either not yet received recognition or never applied for it. To facilitate the interpretation of our results, we only consider full recognitions as successful and exclude individuals with partial or denied recognition from the analysis.

Adopting a standard difference-in-differences approach, we start with the following fixed effects regression to obtain an overall estimate of the impact of recognition:

$$
\mathrm{y}_{i t}=\beta \operatorname{CertRecog}_{i t}+X_{i t}^{\prime} \gamma+\lambda_{t}+\lambda_{p}+\lambda_{i}+\varepsilon_{i t},
$$

where the dependent variable $\mathrm{y}_{i t}$ is an employment indicator, log wages, or an index of the degree of regulation in the observed occupation (explained in more detail in the next section) of individual $i$ at time $t$. The first two outcomes provide general insights into the effects of occupational recognition on immigrants' labor market performance and are particularly important in the context of the poor employment and wage outcomes of immigrants documented in much of the migration literature (for Germany, see e.g. Algan et al., 2010). The last outcome is more specific to our setup and provides insights into the mechanism through which occupational recognition affects labor market outcomes. In particular, it sheds light on the question whether occupational recognition indeed allows immigrants to move into regulated occupations. By considering this outcome first without conditioning on immigrants' employment status, assigning a degree of zero regulation to non-employment, and then conditional on employment, we assess whether the movements into regulated occupations occur primarily out of non-employment or through movements from unregulated to regulated occupations.

The main regressor, CertRecog ${ }_{i t}$, is an indicator variable taking the value one if individual $i$ has a foreign qualification that was recognized before or in time period $t$. For individuals who never apply, this variable is set to zero for all time periods. We are 
interested in identifying $\beta$, the causal effect of occupational recognition on labor market outcomes. For this, we require that, without recognition, the outcomes of individuals who receive full recognition would have evolved in the same way as those of individuals who have either not yet applied or who never apply during our observation window. We assess the validity of this crucial identification assumption by testing for differences in pre-trends between treatment and control group in an event-study-type setup explained below. To control for general changes in labor market conditions, for example due to seasonal variation or business cycle fluctuations, we include time (month $\times$ year) fixed effects $\left(\lambda_{t}\right)$ in equation (1). We also add a full set of months since migration fixed effects $\left(\lambda_{p}\right)$ which capture the dynamic evolution of immigrants' labor market outcomes as a result of their ongoing integration into the host country's economy. To account for time-invariant observable and unobservable heterogeneity, we further include a full set of individual fixed effects $\left(\lambda_{i}\right)$. Their inclusion accounts for much of the personal characteristics associated with better labor market outcomes and the selection into the recognition process, such as the country of origin, the education level before migration, and time-invariant ability and motivation. Finally, we also control for a quadratic term in age ${ }^{3}$ and a proxy for German language proficiency to capture further heterogeneity in the labor market trajectories of immigrants $\left(X_{i t}\right) .{ }^{4}$ Standard errors are clustered at the individual level throughout.

To account for behavioral changes after applying for recognition, we also include an indicator variable that switches on during the period between initial application and final recognition in an alternative specification. After submitting their application, individuals may await the outcome of the recognition process and, if unemployed, search less intensively for a new job or, if employed, reduce their effort or stop working altogether. On the other hand, applying for occupational recognition may already serve as a positive signal in the labor market, improving applicants' labor market outcomes. By including the application dummy, we ensure that our estimates of $\beta$ are not confounded by this type of anticipatory behavior.

While specification (1) provides useful summary measures of the average impact of occupational recognition on employment, wages and the degree of regulation in immigrants' occupations, it is silent about the dynamic process through which the effects of recognition evolve over time. As an extension, we therefore introduce indicator variables for the months around the date of recognition, allowing us to distinguish between short- and long-term labor market effects in an event-study-type setup. We estimate the following

\footnotetext{
${ }^{3}$ Since we include individual and time fixed effects, the linear age effect is not separately identified.

${ }^{4}$ The survey asks respondents to report their German language proficiency for two points in time: the time of the interview and, retrospectively, the time of migrating to Germany. Linearly interpolating between the two data points, we construct proxies for language proficiency at monthly intervals.
} 
specification:

$$
\begin{gathered}
\mathrm{y}_{i t}=\sum_{q=-24}^{-1} \delta_{t-q} \operatorname{CertRecogMth}_{i, t-q}+\delta_{t+25} \operatorname{CertRecog}_{i, t+25} \\
+\sum_{q=1}^{60} \delta_{t-q} \operatorname{CertRecogMth}_{i, t-q}+\delta_{t-61} \operatorname{CertRecog}_{i, t-61} \\
+X_{i t}^{\prime} \gamma+\lambda_{t}+\lambda_{p}+\lambda_{i}+\varepsilon_{i t},
\end{gathered}
$$

where the regressors CertRecogMth $\mathrm{Mt}_{i, t}$ equal one if individual $i$ 's qualification was recognized in period $t-q$ and zero otherwise. We create these indicators starting 24 months before the recognition date and ending 60 months after. For example, CertRecogMth ${ }_{i, t-10}$ is equal to one when the successful recognition happened ten months before period $t$, so that the corresponding estimate of $\delta_{t-10}$ measures the effect of recognition ten months after it was obtained. CertRecog ${ }_{i, t-61}$ is an indicator variable for individuals having a foreign qualification that was recognized before or in period $t-61$. Thus, $\delta_{t-61}$ picks up the long-run average impact of recognition during all months more than five years after the recognition date. Similarly, CertRecog ${ }_{i, t+25}$ is an indicator variable for all periods more than two years before an individual's recognition date. By definition, for non-applicants these indicator variables are all set to zero. Importantly, equation (2) does not include a separate indicator for the time period when recognition was actually obtained $(q=0)$, so that the estimated dynamic effects of recognition are measured relative to this baseline period. ${ }^{5}$ As in the static case, we control for the timing of the application by including a dummy for the application period as an additional regressor.

The main concern regarding our difference-in-differences approach is that unobserved time-varying factors related to both labor market outcomes and the recognition process might confound the estimation results. The inclusion of separate dummy variables for the months prior to recognition allows us to directly assess the relevance of this type of endogeneity as it would typically manifest itself through a violation of the parallel trends assumption. For instance, if some positive labor market shock (e.g. finding a new job) incentivizes an immigrant to apply for recognition (maybe because that would allow the worker to further advance in the new job), diverging trends in labor market outcomes relative to the control group should already materialize prior to the official recognition date. Conversely, if in anticipation of a positive recognition outcome, applicants hold back in the labor market even before submitting their application, a deterioration in their labor market trajectories relative to non-applicants should show up in the pre-recognition period. The observation of small and insignificant estimates in all months prior to the actual recognition date and significant effects moving away from zero soon after would

\footnotetext{
${ }^{5}$ Any level differences in outcomes between treatment and control group in the time period when recognition was obtained are absorbed by the individual fixed effects $\lambda_{i}$, so that the effect of recognition in this baseline period is normalized to zero.
} 
lend support to a causal interpretation of our findings.

While the relatively small sample size of treated individuals with full recognition in our data prevents us from following alternative approaches for the estimation of dynamic treatment effects (see e.g. Fredriksson and Johansson, 2008 or Vikström, 2017), we employ a pooled version of the synthetic control method developed by Abadie et al. (2010) to further test the robustness of our findings. In this approach, each immigrant who receives full recognition is matched to an appropriate control group of immigrants who never applied for recognition but whose labor market outcomes are similar to those of the treated immigrant in the period prior to application. Appendix A.3 provides more details on the implementation of this alternative procedure and documents the corresponding findings, which corroborate our main regression-based results.

\section{Data}

Our empirical analysis is based on a novel longitudinal survey of individuals with migration background in Germany, the IAB-SOEP Migration Sample (Brücker et al., 2014). Conducted by the Institute for Employment Research (IAB) and the German SocioEconomic Panel (SOEP), this survey was started in 2013 and designed to oversample recent immigrants arriving in Germany after 1994. The initial sample comprised around 5,000 first- and second-generation immigrants who were then interviewed annually, with a refreshment sample added every year to deal with sample attrition. The most innovative feature of this data set is its linkage with the administrative data of the IEB (Integrierte Erwerbsbiografien), which comprise full employment histories of all workers covered by the social security system in Germany during the period 1975 to $2014 .{ }^{6}$ For data protection reasons, respondents to the survey component of the data were asked for their prior consent to the record linkage. The overall approval rate was about 52 percent, leading to a linked sample of 2,606 individuals. ${ }^{7}$ Of these, we only consider first-generation immigrants in our analysis and further exclude individuals with missing information on the variables of interest.

The IAB-SOEP Migration Sample suits our analysis for two reasons. First, the survey component contains detailed information on occupational qualifications obtained both before and after migration to Germany. This includes a full module about the recognition process of foreign qualifications with information about the month and year when the application was submitted and the month and year when the final decision was obtained. Second, the social security component of the data allows us to observe an immigrant's entire work history after arrival in Germany. Linking the information about the precise

\footnotetext{
${ }^{6}$ Civil servants, self-employed and military personnel are thus excluded from the IEB.

${ }^{7}$ In Appendix A.2, we show that while selection into the record linkage is systematic in terms of both education and labor market outcomes, it has little impact on our main empirical results.
} 
timing of the recognition process to the spell structure of the administrative data, we observe each individual's labor market outcomes before, during, and after the application process at monthly intervals.

All our monthly outcome variables are constructed from the administrative data of the IEB. Employment is measured as the share of days in a month during which an individual is in contractual employment, thus varying between 0 and $1 .^{8}$ Wages are measured as $\log$ gross daily wages, which we average across all full-time spells in a given month and translate into hourly wages by dividing by $8 .{ }^{9}$ To track the degree of regulation in an immigrant's current occupation, we use an index that represents the employment-weighted share of all 8-digit occupations within each 3-digit occupation of the IEB data that is regulated (licensed). This index, constructed by Vicari (2014) based on registry information for the year 2012, ranges from zero (no 8-digit occupation requiring recognition) to one (all 8-digit occupations requiring recognition) and serves as our proxy for working in a regulated occupation. ${ }^{10}$

Table 1 reports the ten 3-digit occupations with the highest (Panel A) and lowest (Panel B) share of regulated 8-digit occupations. We also report the fraction of the working population employed in each of these occupations, the average hourly wage, the annual rate of wage growth and the rate of wage growth over the first three years in the occupation. Average wages in the ten occupations with the highest degree of regulation are significantly higher than average wages in the ten occupations with the lowest degree of regulation, 11.70 vs. 8.73 euros per hour. In addition, occupations with a higher degree of regulation are also characterized by faster wage growth. Those working in the ten most regulated occupations have an average annual (first 3-year) wage growth of 3.76 (17.05) percent compared to 3.12 (13.45) percent for those working in the ten least regulated occupations. These positive associations between wage levels and wage growth on the one hand and the degree of occupational regulation on the other hand is also more generally detectable in the data. For example, regressing occupation-specific log hourly wages and annual wage growth rates on the regulation index yields positive and statistically significant coefficients of 0.425 (s.e. 0.001) and 0.373 (s.e. 0.020).

We restrict our sample to foreign-born individuals who either eventually receive full recognition or never apply during the observation window. ${ }^{11}$ From this group, we select all individuals who permanently migrated to Germany aged 18 or older. We further only

\footnotetext{
${ }^{8}$ The IEB data refer only to formal employment so that we cannot observe movements from informal to formal employment.

${ }^{9}$ Wages in the IEB data are right-censored at the social security contribution ceiling. In our context, this is a negligible issue since immigrants in Germany tend to earn wages well below the censoring limit.

${ }^{10}$ Note that if immigrants with full recognition were distributed across 8-digit occupations in the same way as the existing workforce in 2012, the interpretation of our parameter of interest $\beta$ would be the same as in the first-best scenario where the dependent variable was a binary indicator for whether a particular 8-digit occupation was regulated.

${ }^{11}$ The samples of immigrants whose application was denied (33) or who obtained only partial recognition (45) are too small to be studied separately.
} 
Table 1: Regulated and Unregulated Occupations

\begin{tabular}{|c|c|c|c|c|c|}
\hline & $\begin{array}{l}\text { Index of } \\
\text { Regulation } \\
(1)\end{array}$ & $\begin{array}{c}\text { Fraction of } \\
\text { Working Pop. (\%) } \\
(2)\end{array}$ & $\begin{array}{l}\text { Mean } \\
\text { Wage } \\
(3)\end{array}$ & $\begin{array}{c}\text { Annual Rate of } \\
\text { Wage Growth (\%) } \\
(4)\end{array}$ & $\begin{array}{c}\text { First } 3 \text { Years Rate } \\
\text { of Wage Growth (\%) } \\
(5)\end{array}$ \\
\hline \multicolumn{6}{|l|}{ Panel A. First 10 occupations with high degree of regulation: } \\
\hline Occupations in human medicine and dentistry & 1.000 & 0.544 & 16.443 & 4.655 & 32.508 \\
\hline Occupations in veterinary medicine and non-medical animal health practitioners & 1.000 & 0.020 & 12.335 & 4.808 & 22.104 \\
\hline Teachers in schools of general education & 0.991 & 0.351 & 13.228 & 3.143 & 13.089 \\
\hline Occupations in police and criminal investigation, jurisdiction and the penal institution & 0.875 & 0.038 & 9.270 & 2.586 & 10.782 \\
\hline Occupations in nursing, emergency medical services and obstetrics & 0.760 & 2.223 & 9.458 & 3.523 & 19.827 \\
\hline Occupations in technical research and development & 0.753 & 1.752 & 14.015 & 2.795 & 11.179 \\
\hline Occupations in construction scheduling and supervision, and architecture & 0.708 & 0.816 & 13.907 & 2.786 & 13.534 \\
\hline Occupations in geriatric care & 0.628 & 0.102 & 7.034 & 7.272 & 18.007 \\
\hline Occupations in education and social work, and pedagogic specialists in social care work & 0.445 & 2.151 & 9.454 & 3.365 & 17.045 \\
\hline Ship's officers and masters & 0.442 & 0.072 & 11.827 & 2.620 & 12.450 \\
\hline Unweighted average & 0.760 & 0.807 & 11.697 & 3.755 & 17.052 \\
\hline \multicolumn{6}{|l|}{ Panel B. Last 10 occupations with low degree of regulation: } \\
\hline Sales occupations in retail trade (without product specialisation) & 0.000 & 4.262 & 6.844 & 3.689 & 16.922 \\
\hline Driver of vehicles in road traffic & 0.000 & 3.497 & 8.849 & 1.613 & 9.523 \\
\hline Occupations in metalworking & 0.000 & 3.083 & 9.684 & 2.714 & 13.842 \\
\hline Trading occupations & 0.000 & 1.581 & 11.048 & 3.747 & 16.606 \\
\hline Gastronomy occupations & 0.000 & 1.230 & 5.443 & 3.552 & 13.457 \\
\hline Drivers and operators of construction and transportation vehicles and equipment & 0.000 & 0.793 & 9.896 & 1.779 & 6.780 \\
\hline Occupations in housekeeping and consumer counselling & 0.000 & 0.653 & 5.977 & 2.637 & 11.331 \\
\hline Occupations in technical media design & 0.000 & 0.419 & 10.684 & 3.150 & 17.591 \\
\hline Occupations in advertising and marketing & 0.000 & 0.339 & 11.779 & 4.327 & 14.162 \\
\hline Occupations in hotels & 0.000 & 0.272 & 7.074 & 4.007 & 14.243 \\
\hline Unweighted average & 0.000 & 1.613 & 8.728 & 3.121 & 13.446 \\
\hline
\end{tabular}

NOTE.-Summary statistics based on IEB data. Panel A refers to the first 10 occupations with the highest value of the regulation index. Panel B refers to the last 10 occupations with the lowest value of the regulation index. The index is provided by Vicari (2014) and is weighted according to the working population in each occupation in the registry data in 2012. The reported order of occupations is obtained after sorting by the index value and the fraction of the working population. All descriptive values are computed using a 2 percent sample of the full IEB data (including immigrants and natives) and refer to the years 1975-2014. Wages refer to the average real gross hourly wage considering all full-time spells. To mitigate the effect of outliers, we exclude the top and bottom 0.1 percentiles of the wage distribution. The rate of annual wage growth (column 4 ) refers to the within occupation relative difference in wages across two consecutive years. The first 3-year rate of wage growth (column 5) refers to the within occupation wage difference between the first and third year in a given occupation, relative to the first year wage. 
consider observations for individuals aged 25 to 59 and exclude individuals with a known incapacity for work. Finally, we condition on having requested recognition before 2015 to be able to observe post-recognition outcomes in the administrative data (which end in 2014). The final sample consists of 1,218 individuals, of which 140 receive full recognition and 1,078 never apply for recognition, either because they do not have a foreign certificate with which to apply (568) or because they have one but choose not to apply (510).

Table 2 shows descriptive statistics for our estimation sample which comprises individuals who receive full recognition (column 1) and individuals who never apply (column 4). For completeness, we also report descriptives for those who only received partial recognition (column 2) or were denied recognition (column 3). In the full recognition sample, 42.9 percent of the immigrants are male, with an average age of 41.8 years in their last observable spell and 11.0 years of education (excluding tertiary education). The immigrants entered Germany at the age of 31.3 on average, after which they take about 10 months before making an official recognition request. Within, on average, 5.2 months successful immigrants hear about the result of their application but there is substantial variation as indicated by the large standard deviation of 12.1 months.

Table 2 also provides information about each group's labor market outcomes, both during the first year after arrival and across all available time periods. The employment rate generally improves significantly over time, particularly for those who applied for recognition. Average wages in the full recognition and non-applicant group, in contrast, do not increase over time, most likely due to strong positive selection into employment in the first year after arrival. Immigrants who obtain full recognition perform better in terms of employment and wages than all other groups. Most immigrants originate from the former Soviet Union, primarily ethnic Germans, followed by South East Europe. ${ }^{12}$ Given the differences in observable characteristics across groups, we assess the robustness of our main results by restricting the estimation sample to immigrants who eventually all receive full recognition, thus only exploiting the differential timing of their recognition process for identification.

Until the third wave, the IAB-SOEP Migration Sample did not ask respondents for which specific occupation or field of study they requested recognition. That information would allow us to study the labor market effects for regulated and unregulated occupations separately and distinguish the pure signaling effect of occupational recognition from the effect due to better access to certain occupations. What is consistently observed, however, is the general type of certificate for which recognition is requested, differentiating between a college/university degree (57.0 percent), a vocational training (36.0 percent), a doctoral degree ( 4.5 percent) or some other education ( 2.5 percent). In the first two waves of the

${ }^{12}$ The origin group "West" refers to Western Europe, USA, Canada, New Zealand and Australia, with about $80 \%$ coming from Western Europe alone. There are no immigrants from this group with partial recognition since qualification standards across these countries were already largely homogenized during the period analyzed. 
Table 2: Descriptive Statistics by Recognition Outcome

\begin{tabular}{|c|c|c|c|c|}
\hline & $\begin{array}{c}\text { Full } \\
\text { Recognition }\end{array}$ & $\begin{array}{c}\text { Partial } \\
\text { Recognition }\end{array}$ & $\begin{array}{c}\text { Denied } \\
\text { Recognition }\end{array}$ & $\begin{array}{c}\text { Non- } \\
\text { Applicant }\end{array}$ \\
\hline \multicolumn{5}{|l|}{ Panel A. Immigrants: } \\
\hline Male (\%) & $\begin{array}{c}42.9 \\
(49.7)\end{array}$ & $\begin{array}{c}48.5 \\
(50.8)\end{array}$ & $\begin{array}{c}33.3 \\
(47.7)\end{array}$ & $\begin{array}{c}46.6 \\
(49.9)\end{array}$ \\
\hline Years of schooling & $\begin{array}{l}11.0 \\
(1.7)\end{array}$ & $\begin{array}{l}10.1 \\
(2.0)\end{array}$ & $\begin{array}{l}10.0 \\
(1.4)\end{array}$ & $\begin{array}{l}10.4 \\
(2.1)\end{array}$ \\
\hline Proficiency in German (before migration) & $\begin{array}{c}2.2 \\
(1.3)\end{array}$ & $\begin{array}{c}2.3 \\
(1.3)\end{array}$ & $\begin{array}{c}2.2 \\
(1.2)\end{array}$ & $\begin{array}{c}2.0 \\
(1.2)\end{array}$ \\
\hline Age last spell & $\begin{array}{l}41.8 \\
(9.6)\end{array}$ & $\begin{array}{l}43.1 \\
(8.5)\end{array}$ & $\begin{array}{l}44.9 \\
(8.5)\end{array}$ & $\begin{array}{l}41.2 \\
(9.6)\end{array}$ \\
\hline Age at first migration & $\begin{array}{l}31.3 \\
(7.4)\end{array}$ & $\begin{array}{l}29.5 \\
(7.2)\end{array}$ & $\begin{array}{l}32.8 \\
(8.5)\end{array}$ & $\begin{array}{l}31.3 \\
(8.9)\end{array}$ \\
\hline Age at request of recognition & $\begin{array}{l}32.1 \\
(7.5)\end{array}$ & $\begin{array}{l}32.3 \\
(9.8)\end{array}$ & $\begin{array}{l}35.4 \\
(9.2)\end{array}$ & \\
\hline Time request to result (months) & $\begin{array}{c}5.2 \\
(12.1)\end{array}$ & $\begin{array}{c}12.2 \\
(23.2)\end{array}$ & $\begin{array}{c}4.1 \\
(6.8)\end{array}$ & \\
\hline West $(\%)$ & $\begin{array}{c}9.3 \\
(29.1)\end{array}$ & $\begin{array}{c}0.0 \\
(0.0)\end{array}$ & $\begin{array}{c}2.2 \\
(14.9)\end{array}$ & $\begin{array}{c}12.2 \\
(32.7)\end{array}$ \\
\hline East Europe (\%) & $\begin{array}{c}12.9 \\
(33.6)\end{array}$ & $\begin{array}{c}12.1 \\
(33.1)\end{array}$ & $\begin{array}{c}4.4 \\
(20.8)\end{array}$ & $\begin{array}{c}16.3 \\
(37.0)\end{array}$ \\
\hline South East Europe (\%) & $\begin{array}{c}25.7 \\
(43.9)\end{array}$ & $\begin{array}{c}15.2 \\
(36.4)\end{array}$ & $\begin{array}{c}8.9 \\
(28.8)\end{array}$ & $\begin{array}{c}22.4 \\
(41.7)\end{array}$ \\
\hline USSR (\%) & $\begin{array}{c}35.7 \\
(48.1)\end{array}$ & $\begin{array}{l}57.6 \\
(50.2)\end{array}$ & $\begin{array}{c}68.9 \\
(46.8)\end{array}$ & $\begin{array}{c}28.6 \\
(45.2)\end{array}$ \\
\hline Others $(\%)$ & $\begin{array}{c}16.4 \\
(37.2)\end{array}$ & $\begin{array}{c}15.2 \\
(36.4)\end{array}$ & $\begin{array}{l}15.6 \\
(36.7)\end{array}$ & $\begin{array}{c}20.6 \\
(40.5)\end{array}$ \\
\hline \multicolumn{5}{|l|}{ Panel B. Observations - first year in Germany: } \\
\hline Employed (\%) & $\begin{array}{c}29.7 \\
(45.7)\end{array}$ & $\begin{array}{c}13.0 \\
(33.7)\end{array}$ & $\begin{array}{c}7.6 \\
(26.5)\end{array}$ & $\begin{array}{c}31.2 \\
(46.3)\end{array}$ \\
\hline Index regulation $(\%)$ & $\begin{array}{l}10.6 \\
(27.6)\end{array}$ & $\begin{array}{c}3.7 \\
(16.0)\end{array}$ & $\begin{array}{c}1.1 \\
(9.7)\end{array}$ & $\begin{array}{c}2.4 \\
(10.3)\end{array}$ \\
\hline Real hourly wage & $\begin{array}{l}12.7 \\
(5.2)\end{array}$ & $\begin{array}{c}7.5 \\
(2.4)\end{array}$ & $\begin{array}{c}5.2 \\
(2.7)\end{array}$ & $\begin{array}{c}9.0 \\
(5.4)\end{array}$ \\
\hline \multicolumn{5}{|l|}{ Panel C. Observations - average over time: } \\
\hline Employed \% & $\begin{array}{c}66.1 \\
(47.3)\end{array}$ & $\begin{array}{c}52.9 \\
(49.9)\end{array}$ & $\begin{array}{c}53.5 \\
(49.9)\end{array}$ & $\begin{array}{c}58.3 \\
(49.3)\end{array}$ \\
\hline Index regulation $(\%)$ & $\begin{array}{l}13.7 \\
(27.4)\end{array}$ & $\begin{array}{l}11.9 \\
(25.4)\end{array}$ & $\begin{array}{c}7.7 \\
(22.0)\end{array}$ & $\begin{array}{c}3.8 \\
(12.4)\end{array}$ \\
\hline Real hourly wage & $\begin{array}{l}10.7 \\
(5.1)\end{array}$ & $\begin{array}{c}8.8 \\
(4.2)\end{array}$ & $\begin{array}{c}7.5 \\
(3.5)\end{array}$ & $\begin{array}{c}8.7 \\
(4.3)\end{array}$ \\
\hline Individuals & 140 & 33 & 45 & 1,078 \\
\hline
\end{tabular}

NOTE.-The statistics depicted are means with standard deviations reported in parentheses based on one observation per individual in the upper panel and monthly observations in the lower two panels. "Proficiency in German" refers to the mean value of self-reported proficiency in reading, writing, and speaking, where the possible answers take values on a scale between 1 and 5 and correspond to: not at all, badly, okay, well, very well. Employed \% refers to time periods of employment relative to time periods of employment and non-employment. Since information on regulated occupations is not available at the level of the single occupation, each aggregated occupation is assigned an index of the degree of regulation ranging between 0 and 1 (see explanation in the text). The table reports the average regulation index for the respective groups in the sample. Real hourly wages are constructed from daily wage information using only full-time spells and assuming that full-time employment is equivalent to 8 hours per day.

survey, we further observe the type of authority to which immigrants apply, which can proxy for seeking recognition of a regulated or unregulated occupation (see Section 5.3). 
Table 3: Occupational Recognition and Average Labor Market Outcomes

\begin{tabular}{lcccc}
\hline & $\begin{array}{c}\text { Employment } \\
(1)\end{array}$ & $\begin{array}{c}\text { Log Wages } \\
\text { (Full-time) } \\
(2)\end{array}$ & $\begin{array}{c}\text { Regulation } \\
\text { Index } \\
(3)\end{array}$ & $\begin{array}{c}\text { Regulation Index } \\
\text { (Employed) } \\
(4)\end{array}$ \\
\hline Panel A: & & & & \\
$\quad$ Received full recognition & $0.160^{* * *}$ & $0.157^{*}$ & $0.150^{* * *}$ & $0.114^{* *}$ \\
& $(0.050)$ & $(0.080)$ & $(0.033)$ & $(0.056)$ \\
& & & & \\
Panel B: & 0.024 & -0.053 & 0.009 & 0.065 \\
$\quad$ Application period & $(0.067)$ & $(0.105)$ & $(0.035)$ & $(0.065)$ \\
& $0.165^{* * *}$ & 0.141 & $0.152^{* * *}$ & $0.129^{*}$ \\
$\quad$ Received full recognition & $(0.052)$ & $(0.103)$ & $(0.035)$ & $(0.068)$ \\
& & & & \\
& 140 & 114 & 140 & 132 \\
Individuals with recognition & 1,078 & 716 & 1,078 & 949 \\
Individuals without recognition & 1,218 & 830 & 1,218 & 1,081 \\
Individuals total & 136,306 & 50,971 & 129,471 & 74,003 \\
Observations & & & & \\
\hline
\end{tabular}

NOTE.-Panel A reports estimates based on specification (1), Panel B adds an indicator variable for the application period as discussed in the text. The dependent variable is the share of days in employment per month in column (1), log real hourly wages for full-time employees averaged over all spells in a given month in column (2), the index of occupational regulation, assigning a value of zero to the non-employed, in column (3), and the index of occupational regulation in column (4). Additional controls are individual fixed effects, time fixed effects, time since migration fixed effects, age squared, and German language proficiency. Standard errors in parentheses are clustered at the individual level.

$* \mathrm{p}<.10$.

$* * \mathrm{p}<.05$.

$* * * \mathrm{p}<.01$

\section{Main Results}

\section{$5.1 \quad$ Static Effects}

In Panel A of Table 3, we report the static results from specification (1). The estimate in column (1) of Panel A shows that obtaining full occupational recognition increases the share of days in employment per month by 16.0 percentage points, suggesting that occupational recognition helps immigrants find and maintain employment. Adding an indicator variable that switches on during the application period to deal with potential anticipatory behavior of the applicants increases the estimate slightly to 16.5 percentage points (Panel B). The estimate for having applied is close to zero and statistically not significant. While this is a consistent finding throughout, we still focus on the extended specification in most of the remaining discussion. The estimate in column (2) of Panel B indicates that full recognition raises wages by 15.1 percent (14.1 log points). However, it is not statistically significant at conventional levels.

Column (3) shows that after obtaining recognition, immigrants increasingly move into more regulated jobs, with the regulation index increasing by around 15 percentage points on average. Since, for this estimation, we keep non-employed immigrants in the sample and set their regulation indices to zero, some of the positive effect is likely driven by the 
significant movement from non-employment to employment shown in column (1). However, given a mean regulation index of 0.066 for employed immigrants without recognition (0.130 at the 90th percentile), the estimated coefficient is large, suggesting that part of the increase is also driven by movements from unregulated to regulated occupations. To further investigate this, we estimate the effect on the regulation index conditional on employment in column (4). For employed workers, full recognition leads to a move into occupations that are on average 12.9 percentage points more likely to be regulated. The similarity between the results in the last two columns suggests that movements into more regulated occupations occur to a similar extent from non-employment and unregulated jobs.

Our employment and wage effects have to be interpreted with caution. In the presence of heterogeneous returns to occupational recognition, those immigrants with higher expected returns are arguably more likely to apply for recognition. Since our estimation approach does not account for this type of positive selection on gains, for example by using an instrumental variable as in Kugler and Sauer (2005), expanding the recognition policy over a broader set of immigrants would most likely lead to smaller effect sizes than those reported in Table 3. Nevertheless, our estimates are policy-relevant parameters as they reflect the average impact of occupational recognition on those individuals who go through the effort of obtaining recognition - which is the relevant subgroup when endogenous selection into the recognition process is an inherent part of the institutional setup.

Table A.1 in the appendix provides several robustness checks regarding our sample selection procedure by introducing the individual restrictions one at a time. Column (4) restates the main results of Table 3 which are based on the most restrictive sample. In column (1), we only impose the restriction of having migrated after the age of 18 which leads to smaller estimates throughout, especially for wages. In column (2), we then exclude individuals with an incapacity for work which mildly increases the estimated impacts on employment, wages and the regulation index. In column (3), we impose the additional restriction of only including observations for individuals of prime working age (age 25-59) which has little impact on our estimates. Finally, in column (4), we exclude individuals that migrated to Germany more than once which leads to an increase in the wage estimate. We exclude these individuals in our preferred specification since we do not know their labor market outcomes during the time spent outside of Germany. Overall, our sample selection rules do not have a large impact on our main findings. Table A.2 in the appendix further shows that, after controlling for time since migration and individual fixed effects, the inclusion of time fixed effects, the quadratic in age and the German proficiency control has little impact on our estimates. 
Figure 1: Dynamic Effects of Occupational Recognition
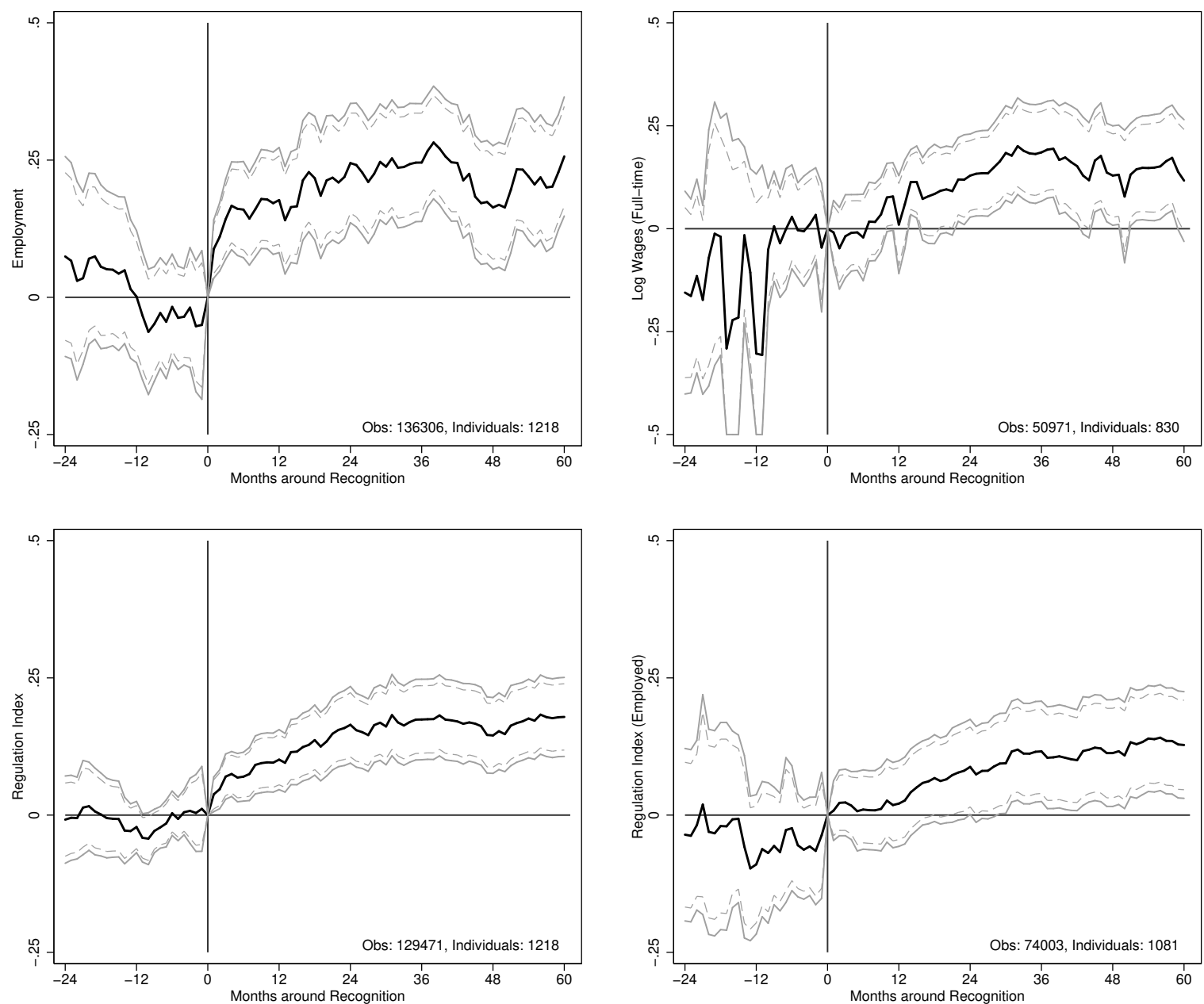

NOTE.-The figures depict the coefficients of the period dummies obtained from estimating specification (2). The dependent variable is the share of days in employment per month (upper left panel), log real hourly wages for full-time employees averaged over all spells in a given month (upper right panel), the index of occupational regulation, assigning a value of zero to the non-employed (lower left panel) and the index of occupational regulation (lower right panel). Additional controls are the long-run average effect after recognition $\left(\operatorname{CertRecog}_{i, t-61}\right)$, the long-run average effect before recognition $($ CertRecog $i, t+25)$, an indicator variable for the application period, individual fixed effects, time fixed effects, time since migration fixed effects, age squared, and German language proficiency. 90\% and 95\% confidence intervals displayed using clustered standard errors at the individual level. Values of the confidence interval in the wage graph are cut at -0.5 for presentation purposes.

\subsection{Dynamic Effects}

We now turn to the results from the dynamic specification in equation (2). In all reported estimations, we include an indicator for the application period and apply the same sample restrictions as for our main static results. For better readability, we show the estimates of $\delta_{t-q}$ graphically together with their confidence intervals. Figure 1 displays the effects of occupational recognition on employment, log real wages, the regulation index including the non-employed and the regulation index conditional on employment in the 24 months before and 60 months after recognition.

After receiving full recognition, the difference in the share of days in employment increases rapidly relative to the control group, reaching 17.1 percentage points after 
12 months (upper left panel). After that, the gap continues to grow but at a slower rate, reaching 24.5 percentage points three years after recognition. This pattern suggests that occupational recognition increases the labor market opportunities of immigrants relatively quickly, and that their employability remains higher even in the long run, most likely due to their wider access to jobs. Reassuringly, there is no discernible difference in employment rates between immigrants who obtain recognition within the following 24 months and immigrants who do not, as indicated by the small and insignificant parameter estimates prior to the recognition date.

The dynamic pattern for log wages (upper right panel) shows a steady increase of the wage differential over time without any immediate jump. After receiving recognition, relative wages are 8.1 percent (7.8 log points) higher after one year and 19.8 percent (18.1 log points) higher after three years. Thereafter, the wage differential relative to those without occupational recognition levels off and coefficients fluctuate around a value of 16 percent. The delayed onset of significant wage gains could be due to the time it takes to locate jobs in the higher paying and now accessible regulated segment of the labor market. It could also be that employers remain initially skeptical regarding the equivalence between foreign and native credentials, and that this skepticism is only overcome with time. While more noisy because of the smaller sample size of employed immigrants, there is once again no evidence of a significant wage gap in the months prior to recognition, especially in the immediately preceeding year, lending credibility to the claim that the subsequent positive wage effects are indeed causally related to the occupational recognition. ${ }^{13}$

The dynamic results with respect to the occupational regulation index in the lower part of the figure provide evidence that immigrants gain employment after recognition by increasingly entering more regulated occupations. When including non-employed individuals in the estimation (lower left panel), there is a rapid increase in the regulation index by 9.6 percentage points within the first 12 months, starting immediately after recognition. Subsequently, the occupations chosen by immigrants with successful recognition continue to be more regulated than those of immigrants' without recognition, with the gap increasing to 17.4 percentage points after three years. These gradual occupational adjustments are likely due to the difficulties for some immigrants of locating suitable jobs in the regulated market segment.

When considering the effect of recognition on the regulation index conditional on employment (lower right panel), the pattern is slightly different. Until about 12 months

\footnotetext{
${ }^{13}$ This result does not contradict the common finding in the literature that, for immigrants, the returns to education acquired abroad are significantly lower than the returns to education acquired in the host country (see Dustmann and Glitz, 2011) and that this regularity can often be attributed to differences in the quality of education across countries (compare e.g. Ferrer et al., 2006; Li and Sweetman, 2014). The recognition process in Germany certifies the equivalence of the foreign qualification with the native reference qualification. By focussing on successful applicants, we are therefore implicitly accounting for differences in educational/training quality.
} 
after recognition, there are no differences in the degree of regulation between immigrants with and without occupational recognition. Only then, the relative movements into more regulated occupations start to become statistically significant. After three years, the relative increase in the probability of working in a regulated occupation reaches 11.5 percentage points and remains approximately constant over the remaining time period. Taken together, these two dynamic regressions show that a successful recognition is helpful in securing employment in regulated occupations. Initially, this is mostly due to nonemployed workers finding jobs in the regulated segment but, with some delay, there is also a shift among employed workers into more regulated occupations. These findings are consistent with the suggested mechanism for the slow wage growth. Securing a regulated occupation does not directly imply higher wages. But the continuous employment in these occupations, which tend to be characterized by higher wages and faster wage growth (see Table 1), generates the observed long-term wage effects.

The evidence in this section suggests that immigrants who have not yet applied for recognition and those who never apply can serve as a reasonable control group in our difference-in-differences setting. As a robustness check, we repeat the entire analysis on a sample that only includes immigrants who eventually all get full recognition. By focussing on this group, we reduce observable and unobservable heterogeneity in the sample and identify the parameters of interest exclusively from the differential timing of the recognition processes across individuals (see Arai and Thoursie, 2009, for a similar approach). As Figure A.1 and Table A.3 in the appendix show, our main results are robust to this alternative identification strategy, with slightly higher employment and wage effects and slightly lower movements into regulated occupations. The results from the pooled synthetic control method reported in Appendix A.3 further confirm that occupational recognition has positive effects on immigrants' employment, hourly wages and probability of working in a regulated occupation.

\subsection{Heterogeneous Effects}

We now study the heterogeneity of the impacts of occupational recognition across several dimensions. Because of the more demanding specifications, some of the estimates have low precision, making it difficult to draw strong conclusions. Panel A of Table 4 presents results where we allow the treatment effect to vary by the type of certificate for which recognition was sought. As discussed before, we do not observe the exact certified occupation or field of study of a successful applicant, but we do observe the broad educational category, allowing us to distinguish four groups: vocational training/apprenticeship, college/university degree, doctoral degree and any other education.

The empirical results suggest that the recognition process is important for most qualifications. Except for the category of other education, all employment and wage effects are positive although often not statistically significant. Doctoral degree holders benefit the 
Table 4: Static Effects by Type of Recognized Certificate and Recognizing Authority

\begin{tabular}{|c|c|c|c|c|}
\hline & $\begin{array}{l}\text { Employment } \\
\text { (1) }\end{array}$ & $\begin{array}{c}\text { Log Wages } \\
\text { (Full-time) } \\
(2)\end{array}$ & $\begin{array}{l}\text { Regulation } \\
\text { Index } \\
(3)\end{array}$ & $\begin{array}{c}\text { Regulation Index } \\
\text { (Employed) } \\
(4)\end{array}$ \\
\hline $\begin{array}{l}\text { Panel A. Recognized Certificate: } \\
\text { Application period }\end{array}$ & $\begin{array}{c}0.026 \\
(0.065)\end{array}$ & $\begin{array}{l}-0.041 \\
(0.104)\end{array}$ & $\begin{array}{c}0.005 \\
(0.035)\end{array}$ & $\begin{array}{c}0.062 \\
(0.066)\end{array}$ \\
\hline $\begin{array}{l}\text { Full recognition of: } \\
\text { vocational training/apprenticeship }\end{array}$ & $\begin{array}{c}0.269^{* * *} \\
(0.055)\end{array}$ & $\begin{array}{c}0.061 \\
(0.174)\end{array}$ & $\begin{array}{c}0.164^{* *} \\
(0.065)\end{array}$ & $\begin{array}{c}0.189 \\
(0.122)\end{array}$ \\
\hline college/university degree & $\begin{array}{c}0.101 \\
(0.070)\end{array}$ & $\begin{array}{c}0.161 \\
(0.122)\end{array}$ & $\begin{array}{c}0.132^{* * *} \\
(0.039)\end{array}$ & $\begin{array}{c}0.135^{* *} \\
(0.065)\end{array}$ \\
\hline doctoral degree & $\begin{array}{c}0.456^{* * *} \\
(0.095)\end{array}$ & $\begin{array}{c}0.305 \\
(0.261)\end{array}$ & $\begin{array}{c}0.431^{* *} \\
(0.178)\end{array}$ & $\begin{array}{c}-0.261 \\
(0.601)\end{array}$ \\
\hline other education & $\begin{array}{c}-0.148 \\
(0.130)\end{array}$ & $\begin{array}{c}0.261^{* * *} \\
(0.028)\end{array}$ & $\begin{array}{c}-0.026^{* * * *} \\
(0.009)\end{array}$ & $\begin{array}{l}-0.008 \\
(0.015)\end{array}$ \\
\hline Individuals with recognition & 140 & 114 & 140 & 132 \\
\hline Individuals without recognition & 1,078 & 716 & 1,078 & 949 \\
\hline Individuals total & 1,218 & 830 & 1,218 & 1,081 \\
\hline Observations & 136,306 & 50,971 & 129,471 & 74,003 \\
\hline \multicolumn{5}{|l|}{ Panel B. Recognizing Authority: } \\
\hline Application period & $\begin{array}{c}0.023 \\
(0.074)\end{array}$ & $\begin{array}{l}-0.043 \\
(0.092)\end{array}$ & $\begin{array}{c}0.005 \\
(0.032)\end{array}$ & $\begin{array}{c}0.063 \\
(0.062)\end{array}$ \\
\hline \multicolumn{5}{|l|}{ Full recognition from: } \\
\hline Chamber of Crafts & $\begin{array}{c}0.096 \\
(0.120)\end{array}$ & $\begin{array}{c}0.327^{* * *} \\
(0.065)\end{array}$ & $\begin{array}{c}0.061 \\
(0.058)\end{array}$ & $\begin{array}{c}0.004 \\
(0.026)\end{array}$ \\
\hline Chamber of Industry and Commerce & $\begin{array}{c}0.258^{* * *} \\
(0.065)\end{array}$ & $\begin{array}{l}-0.005 \\
(0.251)\end{array}$ & $\begin{array}{c}0.067 \\
(0.065)\end{array}$ & $\begin{array}{c}0.193 \\
(0.181)\end{array}$ \\
\hline Office Recognition University Degrees & $\begin{array}{c}0.109 \\
(0.150)\end{array}$ & $\begin{array}{c}0.434^{* * *} \\
(0.106)\end{array}$ & $\begin{array}{c}0.102 \\
(0.065)\end{array}$ & $\begin{array}{c}0.072 \\
(0.280)\end{array}$ \\
\hline Chambers of Physicians, etc. & $\begin{array}{c}0.506^{* * *} \\
(0.038)\end{array}$ & $\begin{array}{c}1.209^{* * *} \\
(0.115)\end{array}$ & $\begin{array}{c}0.440^{* * *} \\
(0.169)\end{array}$ & $\begin{array}{c}0.284^{* * *} \\
(0.064)\end{array}$ \\
\hline other institutions & $\begin{array}{c}0.114 \\
(0.083)\end{array}$ & $\begin{array}{c}0.028 \\
(0.151)\end{array}$ & $\begin{array}{c}0.197^{* * *} \\
(0.062)\end{array}$ & $\begin{array}{c}0.195^{* *} \\
(0.093)\end{array}$ \\
\hline Individuals with recognition & 99 & 82 & 99 & 93 \\
\hline Individuals without recognition & 734 & 518 & 734 & 657 \\
\hline Individuals total & 833 & 600 & 833 & 750 \\
\hline Observations & 122,905 & 46,484 & 116,316 & 66,996 \\
\hline
\end{tabular}

NOTE.-All estimations are based on specification (1) and include an indicator variable for the application period and, in Panel A, separate treatment dummies for individuals with vocational training, university/college degree, doctoral degree and other education as their highest level of foreign training for which recognition was requested. In Panel B, the specification includes separate treatment dummies for recognition through the Chamber of Crafts, Chamber of Industry and Commerce, Office for the Recognition of Foreign University Degrees, Chambers of Physicians, Dentists, Veterinarians and Pharmacists, and Other Institution. The dependent variable is the share of days in employment per month in column (1), log real wages for full-time employees in column (2), the index of occupational regulation, assigning a value of zero to non-employed in column (3), and the index of occupational regulation in column (4). Additional controls are individual fixed effects, time fixed effects, time since migration fixed effects, age squared, and German language proficiency. For individuals with several foreign certificates, the highest in terms of educational value is chosen. Standard errors in parentheses are clustered at the individual level. $* \mathrm{p}<.10$.

$* * \mathrm{p}<.05$.

$* * * \mathrm{p}<.01$.

most with an employment increase of 45.6 percentage points and an insignificant wage increase of 35.7 percent (30.5 log points), followed by the group with vocational training/apprenticeship with an employment effect of 26.9 percentage points and an insignificant wage effect of 6.3 percent (6.1 log points). The movement into regulated occupations 
is similar for the groups with vocational training/apprenticeships and college/university degrees. For those with doctoral studies, the movement from non-employment into regulated occupations is particularly pronounced. Conditional on being employed, the coefficient is negative, although not significant, suggesting that these immigrants remain unemployed until they get a position in their desired regulated occupation.

We next consider heterogeneous effects by the type of authority to which immigrants apply for recognition, which depends on the specific occupation or field of study for which they seek recognition. Different authorities are associated with more or less regulated occupations, allowing us to proxy for the recognition of regulated vs. unregulated occupations. We distinguish five groups: the Chamber of Crafts, the Chamber of Industry and Commerce, and the Office for the Recognition of Foreign University Degrees, all of which are dealing primarily with unregulated occupations, and the Chambers of Physicians, Dentists, Veterinarians and Pharmacists, and Other Institutions, which are dealing primarily with regulated occupations. ${ }^{14}$

Panel B of Table 4 shows that for trained physicians, dentists, veterinarians, and pharmacists, the benefits from obtaining a recognition are substantial, with an employment effect of 50.6 percentage points and a wage effect of 235.0 percent (120.9 log points). This wage effect appears large but is comparable to the findings by Kugler and Sauer (2005) who estimate a return to a medical license for immigrants in Israel between 180 and 340 percent. For workers associated with the medical sector, there is also a large impact on the probability of working in a regulated occupation, with an increase of the regulation index by 28.4 percentage points conditional on employment. This is because physicians, dentists, veterinarians, and pharmacists are all licensed occupations and hence a formal recognition indispensable for working in these occupations.

Immigrants who obtain recognition from the Office for the Recognition of Foreign University Degrees also experience substantial wage gains of 54.3 percent (43.4 log points) but the employment responses are relatively small, reflecting the fact that most of the related occupations are unregulated and thus already accessible prior to obtaining recognition. The same holds for the Chamber of Crafts and the Chamber of Industry and Commerce, where the impact on the probability of working in a regulated occupation, conditional on employment, is again relatively unimportant. Interestingly, however, in both cases there are still sizeable employment and wage effects: the wage effect for recognitions from the Chamber of Crafts is 38.6 percent (32.7 log points) and the employment effect for recognitions from the Chamber of Industry and Commerce is 25.8 percentage points. ${ }^{15}$ Together with the positive wage impact of recognitions from the Office for the Recognition of For-

\footnotetext{
${ }^{14}$ To identify the particular authority responsible for the recognition of a specific occupation we use information from https://www.anerkennung-in-deutschland.de/.

${ }^{15}$ Different labor market institutions such as unionization and other occupation-specific regulations might explain why recognitions from the Chamber of Crafts primarily affect wages while recognitions from the Chamber of Industry and Commerce mostly affect the employment margin.
} 
eign University Degrees, these results suggest that even for unregulated occupations a formal recognition in Germany has significant positive effects on subsequent labor market outcomes, possibly due to its role in signaling immigrants' skills to potential employers.

In Table A.4 in the appendix, we test whether the impact of occupational recognition varies with the level of development of the immigrants' home countries as proxied by GDP per capita. Apart from a small negative estimate in the specification for log wages, the coefficient on the interaction term is always close to zero, indicating that the labor market effects of occupational recognition are quite homogeneous across countries of origin. In Table A.5, we interact the recognition indicator with a measure of German language proficiency at the time of arrival. While generally insignificant, there is some indication that, in terms of employment, applicants with initially lower language proficiency benefit more from the recognition of their foreign qualifications. The reason could be that formal certification resolves employers' uncertainty about immigrants' skills particularly in those cases where the immigrants are unable to verbally convey that information themselves.

\section{Implications for Immigrant Earnings Assimilation}

We now put the significant positive effects of occupational recognition on immigrants' labor market outcomes into perspective by relating them to standard earnings assimilation profiles. For this purpose, we merge a 1 percent random sample of native German workers from the IEB to our IAB-SOEP Migration Sample and jointly estimate the following immigrant and native earnings equations:

Immigrants: $\quad \log w_{i t}=\phi_{m}^{\prime} X_{i t}+\alpha_{m} \cdot \operatorname{age}_{i t}+\beta \cdot \operatorname{ysm}_{i t}+\gamma \cdot \operatorname{ysr}_{i t}+\delta C_{i}+\theta_{m} \pi_{t}+\varepsilon_{i t}$

Natives:

$$
\log w_{i t}=\phi_{n}^{\prime} X_{i t}+\alpha_{n} \cdot \operatorname{age}_{i t}+\theta_{n} \pi_{t}+\varepsilon_{i t} \text {, }
$$

where $w_{i t}$ are total monthly earnings of individual $i$ at time $t, X_{i t}$ is a vector of socioeconomic characteristics (educational attainment ${ }^{16}$, gender, federal state of residence), age ${ }_{i t}$ represents a quartic function of the individual's age, $\mathrm{ysm}_{i t}$ represents a quartic function of the number of years since migration, $\mathrm{ysr}_{i t}$ represents a quartic function of the number of years passed since the result of the recognition process was obtained (set to zero for all immigrants who never applied for recognition), $C_{i}$ is a vector of indicator variables for an immigrant's arrival cohort (1970-1994, 1995-2005, 2005-2013), and $\pi_{t}$ is a vector of year fixed effects. We further impose the standard assumption that period effects are the same for immigrants and natives $\left(\theta_{m}=\theta_{n}\right)$ as suggested by Borjas (1995). We estimate the model using all available monthly native and immigrant observations, clustering standard errors at the individual level. The immigrants in the sample belong to four distinct groups: immigrants who never applied for recognition, immigrants who applied but were

\footnotetext{
${ }^{16}$ We use the imputed education variable obtained from the IP1 algorithm of Fitzenberger et al. (2005).
} 
Figure 2: Effect of Recognition on Immigrant Assimilation Profiles
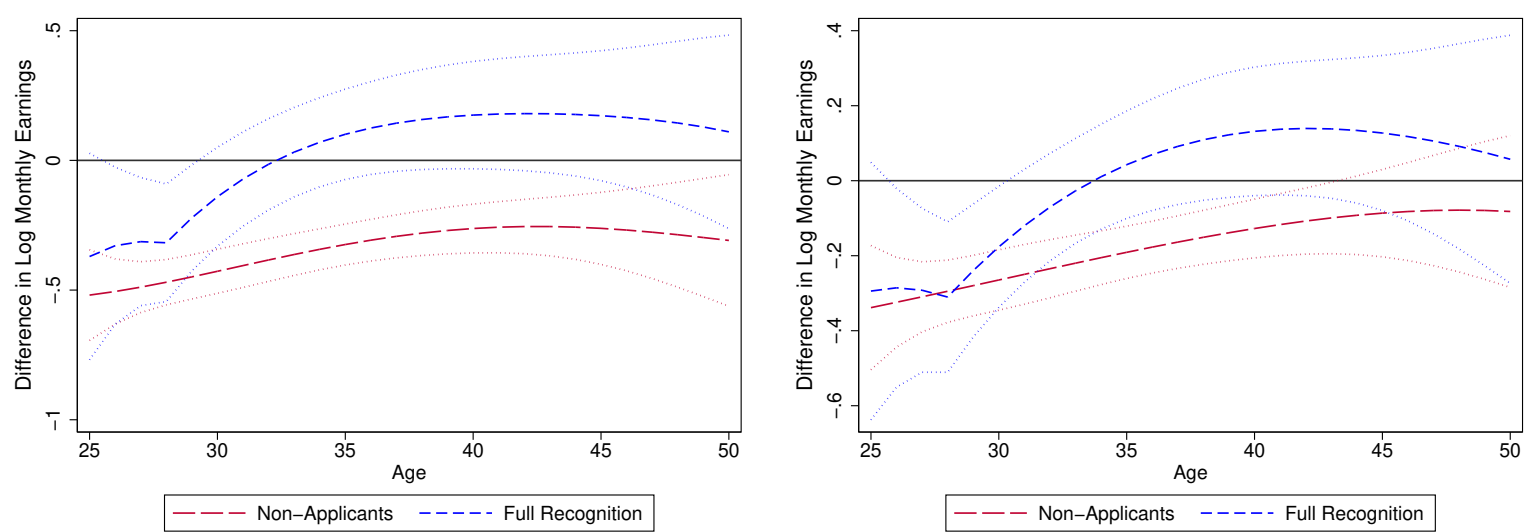

NOTE.-The displayed simulations of the relative earnings profiles in the left and right panel are based on the parameter estimates reported in columns (2) and (4) of Table A.6, respectively. Immigrants are assumed to enter Germany at the age of 25 , with the comparison being relative to natives of the same age. We compute each profile for the mean values of all socioeconomic characteristics in the sample, thus accounting for observable differences in educational attainment, gender, federal state of residence and time period between the different immigrant groups and natives. The intercepts of the different immigrant groups reflect their weighted mean cohort effects. The left panel shows the predicted relative earnings profiles without controlling for occupations, the right panel the profiles after controlling for 3-digit occupations in the IEB data. Full recognition is assumed to occur after three years of residence (the mean duration between arrival and recognition in the assimilation sample). The thin dotted lines represent 95 percent confidence intervals.

denied recognition, immigrants who applied and gained partial recognition, and immigrants who applied and gained full recognition. We allow the age, years since migration and years since recognition profiles to vary between these groups.

Rather than presenting the full regression results, we use the estimates reported in column (2) of Table A.6 in the appendix to predict relative log earnings profiles. We simulate these profiles for immigrants who enter Germany at the age of 25 and compare them to the corresponding profile of natives of the same age. We compute each profile for the mean values of all socioeconomic characteristics in the sample, thus netting out the effects arising from differences in educational attainment, gender, state of residence and time between the different groups of immigrants and natives. The intercepts of the four immigrant groups reflect the weighted means of their cohort effects. ${ }^{17}$ For clarity, the left panel of Figure 2 only depicts the predicted relative earnings profiles of immigrant non-applicants and immigrants who eventually receive full recognition.

Immigrants who never apply for recognition (81.5 percent of the immigrant sample) initially face an earnings gap relative to native Germans of 40.5 percent (-51.9 log points) which steadily declines to around 23.1 percent (-26.3 log points) after 15 years of residence. The earnings of immigrants who eventually obtain full recognition (11.6 percent of the immigrant sample) initially grow at a similar rate but start from a more advantageous position, with an earnings gap upon arrival of only 31.0 percent (-37.1 log points). After obtaining full recognition, which we assume to occur after three years of residence (the

\footnotetext{
${ }^{17}$ Similar to Bratsberg et al. (2006), we allow the returns to education and gender to vary between natives and immigrants but not between different immigrant groups. We further assume the region effects to be the same for immigrants and natives.
} 
average duration between arrival and recognition in the assimilation sample), the speed of convergence of these immigrants' earnings increases substantially (dashed line), leading to a catch-up and eventual overtaking of native earnings after about 8 years and a maximum positive earnings gap of around 19.8 percent (18.0 log points) after 17 years in Germany. However, due to the small sample size, we lack precision in the estimates for immigrants with full recognition, so that after 5 years in the country, the earnings gap is no longer statistically significant.

One reason for why immigrants with full recognition may outperform the average native could be their greater likelihood of working in high-paying occupations, for example in the health sector. Controlling for educational attainment partly accounts for such heterogeneity but even within the group of, say, university-educated workers, immigrants with occupational recognition are likely to be working in more attractive occupations. In the right panel of Figure 2, we depict predicted assimilation profiles from an extended specification in which we additionally control for a full set of 3-digit occupation dummies (see column (4) of Table A.6). Since immigrants' earnings growth is partly driven by their climbing of the occupational ladder, one would generally not want to control for occupation in these types of assimilation regressions. Including occupation fixed effects, however, improves the comparability of natives and immigrants in our sample and, importantly, reveals information about their relative earnings within the same occupations, which could be interpreted as a proxy for the relative quality of the services provided.

As the right panel of Figure 2 shows, accounting for differences in the occupational distribution reduces somewhat the earnings gaps of the different immigrants groups relative to natives. The initial gaps for non-applicants and immigrants with full recognition are now relatively similar, 28.7 percent (-33.8 log points) and 25.4 percent (-29.4 log points) respectively. As before, we observe an acceleration of the speed of assimilation at the time of recognition and an eventual overtaking of native earnings after 9 years, with the maximum gap amounting to statistically not significant 14.9 percent (13.9 log points). The good relative performance of immigrants with full recognition is therefore not just due to their advantageous distribution across occupations. Rather, even conditional on occupation, these immigrants perform at least at the same level as their native counterparts, mitigating concerns that occupational recognition leads to a dilution of occupational standards and suggesting that the formal recognition process in Germany does a reasonable job in ensuring the equivalence of foreign qualifications with their native counterparts.

\section{Conclusion}

Using a novel linked survey-social security data set, we analyze how occupational recognition affects immigrant labor market outcomes in Germany. Our results show large and 
long-lasting positive impacts, with a 24.5 percentage point higher employment rate and a 19.8 percent higher hourly wage three years after obtaining recognition. We document that occupational recognition induces workers to enter more regulated occupations, both directly out of non-employment and through movements from unregulated into regulated occupations. Our heterogeneity analysis indicates that the benefits from formal recognition are not restricted to regulated occupations but extend to unregulated occupations as well. This suggests that, besides granting access to regulated occupations, the certification of foreign qualifications also plays a signalling role in the German labor market, eliminating uncertainty about immigrant workers' skills.

We conclude by showing that occupational recognition leads to a significant acceleration of immigrants' relative earnings growth. Recognizing immigrants' foreign credentials may thus be an effective way of tapping into their human capital and fostering their integration in the host country's economy. More generally, our findings suggest that part of the often substantial employment and wage gaps between immigrants and natives around the world may be due to a lack of formal recognition of occupational qualifications. The sizeable positive wage effects and eventual full convergence to native earnings suggests that foreign credentials, once declared equivalent to native ones, are indeed valued in the German labor market, mitigating fears of a watering-down of occupational standards. 


\section{References}

Abadie, Alberto, Alexis Diamond, and Jens Hainmueller. 2010. Synthetic control methods for comparative case studies: Estimating the effect of California's tobacco control program. Journal of the American Statistical Association 105, no. 490:493-505.

Algan, Yann, Christian Dustmann, Albrecht Glitz, and Alan Manning. 2010. The economic situation of first- and second-generation immigrants in France, Germany, and the UK. Economic Journal 120, no. 542:F4-F30.

Arai, Mahmood and Peter Skogman Thoursie. 2009. Renouncing personal names: An empirical examination of surname change and earnings. Journal of Labor Economics 27, no. 1:127-147.

Borjas, George J. 1995. Assimilation and changes in cohort quality revisited: What happened to immigrant earnings in the 1980s? Journal of Labor Economics 13, no. 2:201245.

Bratsberg, Bernt, Erling Barth, and Oddbjørn Raaum. 2006. Local unemployment and the relative wages of immigrants: Evidence from the Current Population Surveys. Review of Economics and Statistics 88, no. 2:243-263.

Brücker, Herbert, Martin Kroh, Simone Bartsch, Jan Goebel, Simone Kühne, Elisabeth Liebau, Parvati Trübswetter, Ingrid Tucci, and Jürgen Schupp. 2014. The new IAB SOEP Migration Sample: An introduction into the methodology and the contents. SOEP Survey Papers: Series C 216, DIW/SOEP, Berlin.

Bryson, Alex and Morris M. Kleiner. 2010. The regulation of occupations. British Journal of Industrial Relations 48, no. 4:670-675.

Chapman, Bruce J. and Robyn R. Iredale. 1993. Immigrant qualifications: Recognition and relative wage outcomes. International Migration Review 27, no. 2:359-387.

Chiswick, Barry R. and Paul W. Miller. 2003. The complementarity of language and other human capital: Immigrant earnings in Canada. Economics of Education Review 22, no. 5:469-480.

Dustmann, Christian and Tommaso Frattini. 2013. Immigration: The European experience. In Immigration, poverty, and socioeconomic inequality, eds. David Card and Steve Raphael. New York, NY: Russell Sage Foundation, 423-456.

Dustmann, Christian, Tommaso Frattini, and Ian P. Preston. 2013. The effect of immigration along the distribution of wages. Review of Economic Studies 80, no. 1:145-173. 
Dustmann, Christian and Albrecht Glitz. 2011. Migration and education. In Handbook of the economics of education, vol. 4, eds. Eric A. Hanushek, Stephen Machin, and Ludger Woessmann. Amsterdam: Elsevier, 327-439.

Ferrer, Ana, David A. Green, and W. Craig Riddell. 2006. The effect of literacy on immigrant earnings. Journal of Human Resources 41, no. 2:380-410.

Fitzenberger, Bernd, Aderonke Osikominu, and Robert Völter. 2005. Imputation rules to improve the education variable in the IAB employment subsample. FDZMethodenreport 3, Institute for Employment Research, Nuremberg.

Fredriksson, Peter and Per Johansson. 2008. Dynamic treatment assignment: The consequences for evaluations using observational data. Journal of Business 86 Economic Statistics 26, no. 4:435-445.

Friedberg, Rachel M. 2001. The impact of mass migration on the Israeli labor market. Quarterly Journal of Economics 116, no. 4:1373-1408.

Gittleman, Maury, Mark A. Klee, and Morris M. Kleiner. 2018. Analyzing the labor market outcomes of occupational licensing. Industrial Relations 57, no. 1:57-100.

Gomez, Rafael, Morley Gunderson, Xiaoyu Huang, and Tingting Zhang. 2015. Do immigrants gain or lose by occupational licensing? Canadian Public Policy 41:S80-S97.

Kleiner, Morris M. 2017. The influence of occupational licensing and regulation. IZA World of Labor, no. 392:1-10.

Kleiner, Morris M. and Alan B. Krueger. 2013. Analyzing the extent and influence of occupational licensing on the labor market. Journal of Labor Economics 31, no. 2:S173S202.

Koumenta, Maria and Mario Pagliero. 2017. Measuring prevalence and labour market impacts of occupational regulation in the EU. https://ec.europa.eu/growth/content/ measuring-prevalence-and-labour-market-impacts-occupational-regulation-eu-0_ en.

Kugler, Adriana D. and Robert M. Sauer. 2005. Doctors without borders? Relicensing requirements and negative selection in the market for physicians. Journal of Labor Economics 23, no. 3:437-465.

Li, Qing and Arthur Sweetman. 2014. The quality of immigrant source country educational outcomes: Do they matter in the receiving country? Labour Economics 26:81-93. 
Mattoo, Aaditya, Ileana Cristina Neagu, and Caglar Özden. 2008. Brain waste? Educated immigrants in the US labor market. Journal of Development Economics 87, no. 2:255269.

Sweetman, Arthur, James Ted McDonald, and Lesleyanne Hawthorne. 2015. Occupational regulation and foreign qualification recognition: An overview. Canadian Public Policy 41:S1-S13.

Tani, Massimiliano. 2017. Local signals and the returns to foreign education. Economics of Education Review 61:174-190.

2018. Selective immigration, occupational licensing, and labour market outcomes of foreign-trained migrants. IZA Discussion Paper 11370, IZA Institute of Labor Economics, Bonn.

Vicari, Basha. 2014. Degree of standardised certification of occupations: An indicator for measuring institutional characteristics of occupations. FDZ-Methodenreport 4, Institute for Employment Research, Nuremberg.

Vikström, Johan. 2017. Dynamic treatment assignment and evaluation of active labor market policies. Labour Economics 49:42-54. 


\section{Occupational Recognition and Immigrant Labor Market Outcomes*}

\author{
Herbert Brücker \\ Humboldt University, BIM and \\ Institute for Employment Research (IAB)
}

Adrian Lerche

Institute for Employment Research (IAB)

\author{
Albrecht Glitz \\ Universitat Pompeu Fabra, IPEG \\ and Barcelona GSE \\ Agnese Romiti \\ University of Strathclyde - Glasgow
}

\section{- Appendix -}

*Contact details: Herbert Brücker: herbert.bruecker@iab.de, Albrecht Glitz: albrecht.glitz@upf.edu, Adrian Lerche: adrian.lerche@iab.de, Agnese Romiti: agnese.romiti@strath.ac.uk. 


\section{A.1 Tables and Figures}

Table A.1: Impact of Different Sample Selection Procedures

\begin{tabular}{|c|c|c|c|c|}
\hline & $\begin{array}{c}\text { Migration } \\
\text { after age } 17 \\
\text { (1) }\end{array}$ & $\begin{array}{c}(1)+\text { excl. } \\
\text { incapacity } \\
(2)\end{array}$ & $\begin{array}{c}(2)+\text { working } \\
\text { age } \\
(3)\end{array}$ & $\begin{array}{c}(3)+\text { stay } \\
\text { in Germany } \\
(4)\end{array}$ \\
\hline \multicolumn{5}{|l|}{ Panel A. Employment: } \\
\hline Application period & $\begin{array}{c}-0.008 \\
(0.058)\end{array}$ & $\begin{array}{c}0.023 \\
(0.055)\end{array}$ & $\begin{array}{c}0.051 \\
(0.060)\end{array}$ & $\begin{array}{c}0.024 \\
(0.067)\end{array}$ \\
\hline Received full recognition & $\begin{array}{c}0.149^{* * *} \\
(0.055)\end{array}$ & $\begin{array}{c}0.172^{* * *} \\
(0.049)\end{array}$ & $\begin{array}{c}0.162^{* * *} \\
(0.055)\end{array}$ & $\begin{array}{c}0.165^{* * *} \\
(0.052)\end{array}$ \\
\hline Individuals with recognition & 166 & 159 & 158 & 140 \\
\hline Individuals without recognition & 1,304 & 1,253 & 1,188 & 1,078 \\
\hline Individuals total & 1,470 & 1,412 & 1,346 & 1,218 \\
\hline Observations & 189,027 & 176,994 & 155,566 & 136,306 \\
\hline \multicolumn{5}{|l|}{ Panel B. Log Wages (Full-time): } \\
\hline Application period & $\begin{array}{l}-0.139 \\
(0.097)\end{array}$ & $\begin{array}{l}-0.117 \\
(0.098)\end{array}$ & $\begin{array}{l}-0.113 \\
(0.102)\end{array}$ & $\begin{array}{l}-0.053 \\
(0.105)\end{array}$ \\
\hline Received full recognition & $\begin{array}{c}0.070 \\
(0.096)\end{array}$ & $\begin{array}{c}0.089 \\
(0.103)\end{array}$ & $\begin{array}{l}0.086 \\
(0.106)\end{array}$ & $\begin{array}{c}0.141 \\
(0.103)\end{array}$ \\
\hline Individuals with recognition & 135 & 129 & 128 & 114 \\
\hline Individuals without recognition & 884 & 847 & 796 & 716 \\
\hline Individuals total & 1,019 & 976 & 924 & 830 \\
\hline Observations & 62,982 & 59,280 & 55,765 & 50,971 \\
\hline \multicolumn{5}{|l|}{ Panel C. Regulation Index: } \\
\hline Application period & $\begin{array}{c}0.020 \\
(0.029)\end{array}$ & $\begin{array}{c}0.025 \\
(0.030)\end{array}$ & $\begin{array}{c}0.028 \\
(0.033)\end{array}$ & $\begin{array}{c}0.009 \\
(0.035)\end{array}$ \\
\hline Received full recognition & $\begin{array}{c}0.144^{* * *} \\
(0.032)\end{array}$ & $\begin{array}{c}0.153^{* * *} \\
(0.033)\end{array}$ & $\begin{array}{c}0.157^{* * *} \\
(0.037)\end{array}$ & $\begin{array}{c}0.152^{* * *} \\
(0.035)\end{array}$ \\
\hline Individuals with recognition & 166 & 159 & 158 & 140 \\
\hline Individuals without recognition & 1,304 & 1,253 & 1,188 & 1,078 \\
\hline Individuals total & 1,470 & 1,412 & 1,346 & 1,218 \\
\hline Observations & 181,088 & 169,313 & 148,378 & 129,471 \\
\hline \multicolumn{5}{|c|}{ Panel D. Regulation Index (Employed): } \\
\hline Application period & $\begin{array}{c}0.041 \\
(0.051)\end{array}$ & $\begin{array}{c}0.045 \\
(0.053)\end{array}$ & $\begin{array}{c}0.040 \\
(0.057)\end{array}$ & $\begin{array}{c}0.065 \\
(0.065)\end{array}$ \\
\hline Received full recognition & $\begin{array}{c}0.118^{* *} \\
(0.054)\end{array}$ & $\begin{array}{c}0.123^{* *} \\
(0.056)\end{array}$ & $\begin{array}{c}0.123^{* *} \\
(0.059)\end{array}$ & $\begin{array}{l}0.129^{*} \\
(0.068)\end{array}$ \\
\hline Individuals with recognition & 159 & 152 & 150 & 132 \\
\hline Individuals without recognition & 1,157 & 1,116 & 1,048 & 949 \\
\hline Individuals total & 1,316 & 1,268 & 1,198 & 1,081 \\
\hline Observations & 92,140 & 87,004 & 80,782 & 74,003 \\
\hline
\end{tabular}

NOTE.-All estimations are based on specification (1) and include an indicator variable for the application period. The dependent variable is the share of days in employment per month in Panel A, log real hourly wages for full-time employees averaged over all spells in a given month in Panel B, the index of occupational regulation, assigning a value of zero to the non-employed, in Panel C, and the index of occupational regulation in Panel D. Additional controls are individual fixed effects, time fixed effects, time since migration fixed effects, age squared, and German language proficiency. The sample comprises immigrants who either receive full recognition or never apply. Additional selection rules are described in the heading. Standard errors in parentheses are clustered at the individual level.

$* \mathrm{p}<.10$.

$* * \mathrm{p}<.05$

$* * * \mathrm{p}<.01$. 
Table A.2: Impact of Control Variables

\begin{tabular}{|c|c|c|c|c|c|c|}
\hline & $(1)$ & $(2)$ & $(3)$ & $(4)$ & (5) & $(6)$ \\
\hline \multicolumn{7}{|l|}{ Panel A. Employment: } \\
\hline Application period & $\begin{array}{c}-0.237^{* * *} \\
(0.066)\end{array}$ & $\begin{array}{c}-0.108^{*} \\
(0.065)\end{array}$ & $\begin{array}{c}0.032 \\
(0.066)\end{array}$ & $\begin{array}{c}0.027 \\
(0.066)\end{array}$ & $\begin{array}{c}0.024 \\
(0.066)\end{array}$ & $\begin{array}{c}0.024 \\
(0.067)\end{array}$ \\
\hline Received full recognition & $\begin{array}{c}0.153^{* * *} \\
(0.034)\end{array}$ & $\begin{array}{c}0.127^{* * *} \\
(0.035)\end{array}$ & $\begin{array}{c}0.170^{* * *} \\
(0.051)\end{array}$ & $\begin{array}{c}0.166^{* * *} \\
(0.051)\end{array}$ & $\begin{array}{c}0.164^{* * *} * \\
(0.052)\end{array}$ & $\begin{array}{c}0.165^{* * *} \\
(0.052)\end{array}$ \\
\hline Individuals with recognition & 140 & 140 & 140 & 140 & 140 & 140 \\
\hline Individuals without recognition & 1,078 & 1,078 & 1,078 & 1,078 & 1,078 & 1,078 \\
\hline Individuals total & 1,218 & 1,218 & 1,218 & 1,218 & 1,218 & 1,218 \\
\hline Observations & 136,306 & 136,306 & 136,306 & 136,306 & 136,306 & 136,306 \\
\hline \multicolumn{7}{|l|}{ Panel B. Log Wages (Full-time): } \\
\hline Application period & $\begin{array}{c}-0.061 \\
(0.167)\end{array}$ & $\begin{array}{c}-0.026 \\
(0.161)\end{array}$ & $\begin{array}{l}-0.034 \\
(0.101)\end{array}$ & $\begin{array}{l}-0.047 \\
(0.105)\end{array}$ & $\begin{array}{l}-0.053 \\
(0.105)\end{array}$ & $\begin{array}{l}-0.053 \\
(0.105)\end{array}$ \\
\hline Received full recognition & $\begin{array}{c}0.242^{* * *} \\
(0.056)\end{array}$ & $\begin{array}{c}0.242^{* * *} \\
(0.055)\end{array}$ & $\begin{array}{c}0.136 \\
(0.101)\end{array}$ & $\begin{array}{c}0.148 \\
(0.104)\end{array}$ & $\begin{array}{c}0.141 \\
(0.103)\end{array}$ & $\begin{array}{c}0.141 \\
(0.103)\end{array}$ \\
\hline Individuals with recognition & 114 & 114 & 114 & 114 & 114 & 114 \\
\hline Individuals without recognition & 716 & 716 & 716 & 716 & 716 & 716 \\
\hline Individuals total & 830 & 830 & 830 & 830 & 830 & 830 \\
\hline Observations & 50,971 & 50,971 & 50,971 & 50,971 & 50,971 & 50,971 \\
\hline \multicolumn{7}{|l|}{ Panel C. Regulation Index: } \\
\hline Application period & $\begin{array}{c}0.019 \\
(0.018)\end{array}$ & $\begin{array}{c}0.023 \\
(0.019)\end{array}$ & $\begin{array}{c}0.013 \\
(0.035)\end{array}$ & $\begin{array}{c}0.011 \\
(0.035)\end{array}$ & $\begin{array}{c}0.009 \\
(0.035)\end{array}$ & $\begin{array}{c}0.009 \\
(0.035)\end{array}$ \\
\hline Received full recognition & $\begin{array}{c}0.117 * * * \\
(0.022)\end{array}$ & $\begin{array}{c}0.117^{* * *} * \\
(0.021)\end{array}$ & $\begin{array}{c}0.155^{* * *} \\
(0.035)\end{array}$ & $\begin{array}{c}0.153^{* * *} \\
(0.035)\end{array}$ & $\begin{array}{c}0.152^{* * *} \\
(0.035)\end{array}$ & $\begin{array}{c}0.152^{* * *} \\
(0.035)\end{array}$ \\
\hline Individuals with recognition & 140 & 140 & 140 & 140 & 140 & 140 \\
\hline Individuals without recognition & 1,078 & 1,078 & 1,078 & 1,078 & 1,078 & 1,078 \\
\hline Individuals total & 1,218 & 1,218 & 1,218 & 1,218 & 1,218 & 1,218 \\
\hline Observations & 129,471 & 129,471 & 129,471 & 129,471 & 129,471 & 129,471 \\
\hline \multicolumn{7}{|c|}{ Panel D. Regulation Index (Employed): } \\
\hline Application period & $\begin{array}{c}0.096^{*} \\
(0.054)\end{array}$ & $\begin{array}{c}0.082 \\
(0.053)\end{array}$ & $\begin{array}{c}0.068 \\
(0.066)\end{array}$ & $\begin{array}{c}0.066 \\
(0.066)\end{array}$ & $\begin{array}{c}0.065 \\
(0.066)\end{array}$ & $\begin{array}{c}0.065 \\
(0.065)\end{array}$ \\
\hline Received full recognition & $\begin{array}{c}0.149^{* * *} \\
(0.030)\end{array}$ & $\begin{array}{c}0.150^{* * *} \\
(0.029)\end{array}$ & $\begin{array}{l}0.131^{*} \\
(0.068)\end{array}$ & $\begin{array}{l}0.130^{*} \\
(0.068)\end{array}$ & $\begin{array}{l}0.129^{*} \\
(0.068)\end{array}$ & $\begin{array}{l}0.129^{*} \\
(0.068)\end{array}$ \\
\hline Individuals with recognition & 132 & 132 & 132 & 132 & 132 & 132 \\
\hline Individuals without recognition & 949 & 949 & 949 & 949 & 949 & 949 \\
\hline Individuals total & 1,081 & 1,081 & 1,081 & 1,081 & 1,081 & 1,081 \\
\hline Observations & 74,003 & 74,003 & 74,003 & 74,003 & 74,003 & 74,003 \\
\hline Time since migration fixed effects & & Yes & Yes & Yes & Yes & Yes \\
\hline Individual fixed effects & & & Yes & Yes & Yes & Yes \\
\hline Time fixed effects & & & & Yes & Yes & Yes \\
\hline Age squared & & & & & Yes & Yes \\
\hline German language proficiency & & & & & & Yes \\
\hline
\end{tabular}

NOTE.-All estimations are based on specification (1) and include an indicator variable for the application period. The dependent variable is the share of days in employment per month in Panel A, log real hourly wages for full-time employees averaged over all spells in a given month in Panel B, the index of occupational regulation, assigning a value of zero to the non-employed, in Panel C, and the index of occupational regulation in Panel D. Sample selection is the same as in Table 3. Additional controls are specified at the bottom of each column. Standard errors in parentheses are clustered at the individual level.

$* \mathrm{p}<.10$.

$* * \mathrm{p}<.05$

$* * * \mathrm{p}<.01$ 
Table A.3: Static Effects of Occupational Recognition Excluding Non-Applicants

\begin{tabular}{lcccc}
\hline & $\begin{array}{c}\text { Employment } \\
(1)\end{array}$ & $\begin{array}{c}\text { Log Wages } \\
\text { Full-time })\end{array}$ & $\begin{array}{c}\text { Regulation } \\
\text { Index } \\
(2)\end{array}$ & $\begin{array}{c}\text { Regulation Index } \\
\text { (Employed }) \\
(4)\end{array}$ \\
\hline Panel A: & & & & \\
Received full recognition & $0.186^{* * *}$ & $0.154^{*}$ & $0.137^{* * *}$ & 0.105 \\
& $(0.062)$ & $(0.081)$ & $(0.037)$ & $(0.064)$ \\
Panel B: & & & & \\
Application period & 0.020 & 0.031 & -0.007 & 0.048 \\
& $(0.067)$ & $(0.097)$ & $(0.040)$ & $(0.071)$ \\
Received full recognition & $0.191^{* * *}$ & 0.163 & $0.136^{* * *}$ & 0.116 \\
& $(0.065)$ & $(0.105)$ & $(0.041)$ & $(0.077)$ \\
& & & & 132 \\
Individuals & 140 & 114 & 140 & 10,581 \\
Observations & 17,170 & 8,563 & 16,405 & \\
\hline
\end{tabular}

NOTE.-Panel A reports estimates based on specification (1), Panel B adds an indicator variable for the application period as discussed in the text. The dependent variable is the share of days in employment per month in column (1), log real hourly wages for full-time employees averaged over all spells in a given month in column (2), the index of occupational regulation, assigning a value of zero to the non-employed, in column (3), and the index of occupational regulation in column (4). Additional controls are individual fixed effects, time fixed effects, time since migration fixed effects, age squared, and German language proficiency. The sample comprises only immigrants who eventually receive full recognition, and who migrated to Germany at the age of at least 18, stayed in Germany after arrival and do not have any reported incapacity for work. Observations are only included when migrant's age is at least 25 and less than 60. Standard errors in parentheses are clustered at the individual level.

$* \mathrm{p}<.10$.

$* * \mathrm{p}<.05$.

$* * * \mathrm{p}<.01$. 
Table A.4: Static Effects by GDP in Country of Origin

\begin{tabular}{lcccc}
\hline & $\begin{array}{c}\text { Employment } \\
(1)\end{array}$ & $\begin{array}{c}\text { Log Wages } \\
\text { Full-time) } \\
(2)\end{array}$ & $\begin{array}{c}\text { Regulation } \\
\text { Index } \\
(3)\end{array}$ & $\begin{array}{c}\text { Regulation Index } \\
\text { (Employed) } \\
(4)\end{array}$ \\
\hline Application period & 0.031 & -0.053 & 0.007 & 0.068 \\
& $(0.068)$ & $(0.100)$ & $(0.035)$ & $(0.072)$ \\
Received full recognition & $0.177^{* * *}$ & 0.143 & $0.149^{* * *}$ & $0.138^{*}$ \\
& $(0.052)$ & $(0.100)$ & $(0.035)$ & $(0.077)$ \\
Received full recognition & -0.000 & $-0.016^{* *}$ & 0.001 & 0.000 \\
$\times$ GDP/capita (demeaned) & $(0.004)$ & $(0.007)$ & $(0.004)$ & $(0.003)$ \\
& & & & 5.76 \\
Mean GDP/capita & 5.49 & 5.80 & 5.56 & 125 \\
Individuals with recognition & 133 & 107 & 133 & 889 \\
Individuals without recognition & 1,007 & 673 & 1,007 & 1,014 \\
Individuals total & 1,140 & 780 & 1,140 & 68,362 \\
Observations & 124,982 & 46,925 & 118,439 & \\
\hline
\end{tabular}

NOTE.-All estimations are based on specification (1) and include an indicator variable for the application period and an interaction term with demeaned GDP per capita. The dependent variable is the share of days in employment per month in column (1), log real hourly wages for full-time employees averaged over all spells in a given month in column (2), the index of occupational regulation, assigning a value of zero to the non-employed in column (3), and the index of occupational regulation in column (4). Additional controls are individual fixed effects, time fixed effects, time since migration fixed effects, age squared, and German language proficiency. The variable GDP/capita takes the respective value for the year of immigration for each individual. The mean GDP/capita is the average among included individuals weighted by their number of observations (in \$1,000). GDP information is taken from the World Bank database. Standard errors in parentheses are clustered at the individual level.

$* \mathrm{p}<.10$.

$* * \mathrm{p}<.05$.

$* * * \mathrm{p}<.01$

Table A.5: Language Proficiency at the Time of Arrival

\begin{tabular}{|c|c|c|c|c|}
\hline & $\begin{array}{l}\text { Employment } \\
\text { (1) }\end{array}$ & $\begin{array}{c}\text { Log Wages } \\
\text { (Full-time) } \\
(2)\end{array}$ & $\begin{array}{l}\text { Regulation } \\
\text { Index } \\
(3)\end{array}$ & $\begin{array}{c}\text { Regulation Index } \\
\text { (Employed) } \\
(4)\end{array}$ \\
\hline Application period & $\begin{array}{c}0.039 \\
(0.064)\end{array}$ & $\begin{array}{l}-0.033 \\
(0.105)\end{array}$ & $\begin{array}{c}0.010 \\
(0.034)\end{array}$ & $\begin{array}{c}0.066 \\
(0.068)\end{array}$ \\
\hline Received full recognition & $\begin{array}{c}0.189^{* * *} \\
(0.044)\end{array}$ & $\begin{array}{c}0.154 \\
(0.101)\end{array}$ & $\begin{array}{c}0.154^{* * *} \\
(0.036)\end{array}$ & $\begin{array}{l}0.131^{*} \\
(0.070)\end{array}$ \\
\hline $\begin{array}{l}\text { Received full recognition } \\
\times \text { Proficiency before migration (demeaned) }\end{array}$ & $\begin{array}{r}-0.074^{*} \\
(0.040)\end{array}$ & $\begin{array}{c}0.060 \\
(0.085)\end{array}$ & $\begin{array}{l}-0.006 \\
(0.027)\end{array}$ & $\begin{array}{l}-0.005 \\
(0.042)\end{array}$ \\
\hline Mean Proficiency before migration & 2.02 & 2.22 & 2.01 & 2.13 \\
\hline Individuals with recognition & 140 & 114 & 140 & 132 \\
\hline Individuals without recognition & 1,078 & 716 & 1,078 & 949 \\
\hline Individuals total & 1,218 & 830 & 1,218 & 1,081 \\
\hline Observations & 136,306 & 50,971 & 129,471 & 74,003 \\
\hline
\end{tabular}

NOTE.-All estimations are based on specification (1) and include an indicator variable for the application period and an interaction term for language proficiency before migration. The dependent variable is the share of days in employment per month in column (1), log real hourly wages for full-time employees averaged over all spells in a given month in column (2), the index of occupational regulation, assigning a value of zero to non-employed in column (3), and the index of occupational regulation in column (4). Additional controls are individual fixed effects, time fixed effects, time since migration fixed effects, age squared, and German language proficiency. For individuals with several foreign certificates, the highest in terms of educational value is chosen. Language proficiency at the time of arrival is measured on a scale from 1 (low) to 5 (high) and introduced as a continuous variable. The mean of language proficiency before migration is the average among included individuals weighted by their number of observations. Standard errors in parentheses are clustered at the individual level.

$* \mathrm{p}<.10$.

$* * \mathrm{p}<.05$.

$* * * \mathrm{p}<.01$. 
Table A.6: Assimilation Regressions

\begin{tabular}{|c|c|c|c|c|c|c|c|c|}
\hline \multirow[b]{3}{*}{ Never } & \multicolumn{4}{|c|}{ No Occupation Controls } & \multicolumn{4}{|c|}{ With Occupation Controls } \\
\hline & \multicolumn{2}{|c|}{ (1) } & \multicolumn{2}{|c|}{$(2)$} & \multicolumn{2}{|c|}{$(3)$} & \multicolumn{2}{|c|}{$(4)$} \\
\hline & 1.181 & $(6.285)$ & 1.136 & $(6.285)$ & -1.361 & $(5.923)$ & -1.373 & $(5.925)$ \\
\hline Denied & 24.739 & (30.449) & 33.459 & $(35.290)$ & 39.807 & (31.468) & 56.423 & $(34.324)$ \\
\hline Partial & 7.870 & $(29.353)$ & 17.987 & $(28.714)$ & 36.512 & $(25.968)$ & 42.050 & (26.109) \\
\hline Full & -18.383 & $(14.747)$ & -12.497 & $(14.999)$ & -12.629 & $(12.603)$ & -8.996 & $(12.717)$ \\
\hline Never $\times$ YSM & 0.004 & $(0.028)$ & 0.002 & $(0.028)$ & 0.004 & $(0.025)$ & 0.004 & $(0.025)$ \\
\hline Denied $\times$ YSM & -0.045 & $(0.197)$ & 0.071 & $(0.198)$ & -0.074 & $(0.239)$ & 0.152 & $(0.248)$ \\
\hline Partial × YSM & 0.235 & $(0.151)$ & 0.190 & $(0.172)$ & $0.341^{*}$ & $(0.172)$ & 0.328 & $(0.175)$ \\
\hline Full $\times$ YSM & -0.003 & $(0.058)$ & -0.031 & $(0.058)$ & -0.037 & $(0.051)$ & -0.061 & $(0.051)$ \\
\hline Never $\times \mathrm{YSM}^{2} / 10$ & 0.014 & $(0.040)$ & 0.017 & $(0.040)$ & 0.007 & $(0.036)$ & 0.007 & $(0.036)$ \\
\hline Denied $\times \mathrm{YSM}^{2} / 10$ & 0.230 & $(0.353)$ & 0.011 & $(0.365)$ & 0.268 & $(0.424)$ & -0.090 & $(0.439)$ \\
\hline Partial $\times \mathrm{YSM}^{2} / 10$ & -0.330 & $(0.245)$ & -0.278 & $(0.254)$ & -0.473 & $(0.256)$ & -0.436 & $(0.252)$ \\
\hline Full $\times \mathrm{YSM}^{2} / 10$ & 0.044 & $(0.075)$ & -0.073 & $(0.074)$ & 0.071 & $(0.068)$ & -0.029 & $(0.070)$ \\
\hline Never $\times \mathrm{YSM}^{3} / 100$ & -0.005 & $(0.021)$ & -0.007 & $(0.021)$ & -0.003 & $(0.019)$ & -0.003 & $(0.019)$ \\
\hline Denied $\times \mathrm{YSM}^{3} / 100$ & -0.203 & $(0.235)$ & -0.066 & $(0.243)$ & -0.230 & $(0.277)$ & -0.015 & $(0.285)$ \\
\hline Partial $\times \mathrm{YSM}^{3} / 100$ & 0.208 & $(0.161)$ & 0.168 & $(0.147)$ & 0.268 & $(0.156)$ & 0.228 & $(0.149)$ \\
\hline Full $\times \mathrm{YSM}^{3} / 100$ & -0.022 & $(0.035)$ & $0.088^{*}$ & $(0.041)$ & -0.033 & $(0.033)$ & 0.052 & $(0.038)$ \\
\hline Never $\times \mathrm{YSM}^{4} / 1000$ & 0.000 & $(0.003)$ & 0.001 & $(0.003)$ & 0.000 & $(0.003)$ & 0.000 & $(0.003)$ \\
\hline Denied $\times \mathrm{YSM}^{4} / 1000$ & 0.050 & $(0.050)$ & 0.023 & $(0.052)$ & 0.057 & $(0.058)$ & 0.015 & $(0.060)$ \\
\hline Partial $\times \mathrm{YSM}^{4} / 1000$ & -0.043 & $(0.035)$ & -0.036 & $(0.030)$ & -0.051 & $(0.032)$ & -0.041 & $(0.031)$ \\
\hline Full $\times \mathrm{YSM}^{4} / 1000$ & 0.003 & $(0.005)$ & $-0.018^{*}$ & $(0.007)$ & 0.005 & $(0.005)$ & -0.011 & $(0.006)$ \\
\hline Age & $0.412^{* * *}$ & $(0.011)$ & $0.412^{* * *}$ & $(0.011)$ & $0.388^{* * *}$ & $(0.011)$ & $0.388^{* * *}$ & $(0.011)$ \\
\hline $\mathrm{Age}^{2} / 10$ & $-0.144 * * *$ & $(0.004)$ & $-0.144^{* * *}$ & $(0.004)$ & $-0.137 * * *$ & $(0.004)$ & $-0.137^{* * *}$ & $(0.004)$ \\
\hline $\mathrm{Age}^{3} / 1000$ & $0.226^{* * *}$ & $(0.007)$ & $0.226^{* * *}$ & $(0.007)$ & $0.216^{* * *}$ & $(0.006)$ & $0.216^{* * *}$ & $(0.006)$ \\
\hline $\mathrm{Age}^{4} / 100000$ & $-0.133^{* * *}$ & $(0.004)$ & $-0.133^{* * *}$ & $(0.004)$ & $-0.128^{* * *}$ & $(0.004)$ & $-0.128^{* * *}$ & $(0.004)$ \\
\hline Never $\times$ Age & -0.244 & $(0.647)$ & -0.240 & $(0.647)$ & 0.080 & $(0.605)$ & 0.081 & $(0.605)$ \\
\hline Denied $\times$ Age & -2.317 & $(3.165)$ & -3.249 & $(3.647)$ & -3.940 & $(3.239)$ & -5.704 & $(3.545)$ \\
\hline Partial $\times$ Age & -1.129 & $(2.956)$ & -2.188 & $(2.869)$ & -4.078 & $(2.621)$ & -4.668 & $(2.632)$ \\
\hline Full $\times$ Age & 1.722 & $(1.510)$ & 1.083 & $(1.533)$ & 1.119 & $(1.288)$ & 0.719 & $(1.297)$ \\
\hline Never $\times \mathrm{Age}^{2} / 10$ & 0.120 & $(0.243)$ & 0.119 & $(0.243)$ & -0.025 & $(0.226)$ & -0.026 & $(0.226)$ \\
\hline Denied $\times \mathrm{Age}^{2} / 10$ & 0.739 & $(1.205)$ & 1.093 & $(1.371)$ & 1.384 & $(1.224)$ & 2.044 & $(1.337)$ \\
\hline Partial $\times \mathrm{Age}^{2} / 10$ & 0.514 & $(1.090)$ & 0.924 & $(1.049)$ & 1.615 & $(0.966)$ & 1.846 & $(0.970)$ \\
\hline Full $\times \operatorname{Age}^{2} / 10$ & -0.583 & $(0.565)$ & -0.329 & $(0.573)$ & -0.358 & $(0.482)$ & -0.197 & $(0.485)$ \\
\hline Never $\times \mathrm{Age}^{3} / 1000$ & -0.242 & $(0.399)$ & -0.241 & $(0.399)$ & 0.038 & $(0.367)$ & 0.038 & $(0.367)$ \\
\hline Denied $\times$ Age $^{3} / 1000$ & -0.968 & $(1.992)$ & -1.547 & $(2.235)$ & -2.081 & $(2.015)$ & -3.142 & $(2.190)$ \\
\hline Partial $\times$ Age $^{3} / 1000$ & -0.974 & $(1.749)$ & -1.665 & $(1.660)$ & -2.768 & $(1.549)$ & $-3.162^{*}$ & $(1.550)$ \\
\hline Full $\times \mathrm{Age}^{3} / 1000$ & 0.839 & $(0.919)$ & 0.403 & $(0.930)$ & 0.482 & $(0.785)$ & 0.204 & $(0.789)$ \\
\hline Never $\times$ Age $^{4} / 100000$ & 0.171 & $(0.240)$ & 0.170 & $(0.240)$ & -0.022 & $(0.219)$ & -0.022 & $(0.219)$ \\
\hline Denied $\times$ Age $^{4} / 100000$ & 0.428 & $(1.208)$ & 0.773 & $(1.335)$ & 1.131 & $(1.219)$ & 1.754 & $(1.315)$ \\
\hline Partial× Age $^{4} / 100000$ & 0.646 & $(1.032)$ & 1.077 & $(0.963)$ & 1.727 & $(0.912)$ & $1.975^{*}$ & $(0.908)$ \\
\hline Full $\times$ Age $^{4} / 100000$ & -0.438 & $(0.548)$ & -0.166 & $(0.554)$ & -0.233 & $(0.470)$ & -0.059 & $(0.472)$ \\
\hline Medium Edu & $0.262^{* * *}$ & $(0.002)$ & $0.262^{* * *}$ & $(0.002)$ & $0.119 * * *$ & $(0.002)$ & $0.119 * * *$ & $(0.002)$ \\
\hline High Edu & $0.673^{* * *}$ & $(0.003)$ & $0.673^{* * *}$ & $(0.003)$ & $0.347^{* * *}$ & $(0.003)$ & $0.347^{* * *}$ & $(0.003)$ \\
\hline Immigrant $\times$ Medium Edu & -0.055 & $(0.054)$ & -0.053 & $(0.053)$ & 0.035 & $(0.048)$ & 0.036 & $(0.048)$ \\
\hline Immigrant $\times$ High Edu & $0.190 * *$ & $(0.072)$ & $0.184^{*}$ & $(0.073)$ & $0.218^{* * *}$ & $(0.060)$ & $0.216^{* * *}$ & $(0.060)$ \\
\hline Female & $-0.515^{* * *}$ & $(0.002)$ & $-0.515^{* * *}$ & $(0.002)$ & $-0.441 * * *$ & $(0.002)$ & $-0.441 * * *$ & $(0.002)$ \\
\hline Immigrant $\times$ Female & $-0.111^{*}$ & $(0.048)$ & $-0.100^{*}$ & $(0.049)$ & -0.014 & $(0.041)$ & -0.007 & $(0.041)$ \\
\hline Cohort 1970-1994 & 0.123 & $(0.087)$ & 0.145 & $(0.087)$ & 0.103 & $(0.075)$ & 0.105 & $(0.075)$ \\
\hline Cohort 1995-2004 & 0.050 & $(0.057)$ & 0.054 & $(0.057)$ & 0.059 & $(0.053)$ & 0.061 & $(0.053)$ \\
\hline Denied × YSR & & & -0.017 & $(0.044)$ & & & -0.050 & $(0.048)$ \\
\hline Partial $\times$ YSR & & & 0.027 & $(0.026)$ & & & -0.001 & $(0.023)$ \\
\hline Full $\times$ YSR & & & $0.117 * * *$ & $(0.026)$ & & & $0.097 * * *$ & $(0.023)$ \\
\hline Denied $\times \mathrm{YSR}^{2} / 10$ & & & 0.023 & $(0.026)$ & & & 0.031 & $(0.023)$ \\
\hline Partial $\times \mathrm{YSR}^{2} / 10$ & & & -0.018 & $(0.048)$ & & & 0.009 & $(0.045)$ \\
\hline Full $\times \mathrm{YSR}^{2} / 10$ & & & -0.010 & $(0.012)$ & & & 0.002 & $(0.009)$ \\
\hline Denied $\times \mathrm{YSR}^{3} / 100$ & & & 0.018 & $(0.031)$ & & & 0.018 & $(0.029)$ \\
\hline Partial $\times \mathrm{YSR}^{3} / 100$ & & & 0.005 & $(0.013)$ & & & 0.008 & $(0.010)$ \\
\hline Full $\times \mathrm{YSR}^{3} / 100$ & & & $-0.057^{* * *}$ & $(0.014)$ & & & $-0.046^{* * *}$ & $(0.012)$ \\
\hline Denied $\times \mathrm{YSR}^{4} / 1000$ & & & -0.012 & $(0.012)$ & & & -0.012 & $(0.011)$ \\
\hline Partial $\times \mathrm{YSR}^{4} / 1000$ & & & 0.008 & $(0.014)$ & & & -0.002 & $(0.012)$ \\
\hline Full $\times \mathrm{YSR}^{4} / 1000$ & & & $0.014^{* * *}$ & $(0.004)$ & & & $0.011^{* * *}$ & $(0.003)$ \\
\hline Constant & $2.231^{* * *}$ & $(0.110)$ & $2.231^{* * *}$ & $(0.110)$ & $1.858^{* * *}$ & $(0.192)$ & $1.858^{* * *}$ & $(0.192)$ \\
\hline R-squared & 0.27 & & 0.27 & & 0.39 & & 0.39 & \\
\hline Observations & $88,283,926$ & & $88,283,926$ & & $86,444,335$ & & $86,444,335$ & \\
\hline
\end{tabular}

NOTE.-The dependent variable is log monthly earnings, conditional on working at least one day in a given month. The omitted categories are males, low educational attainment, immigrant cohort 2005-2014, period 1975. Standard errors are clustered at the individual level. The sample comprises monthly observations of 571,581 individuals in columns (1) and (2) and 569,104 individuals in columns (3) and (4). Standard errors in parentheses are clustered at the individual level.

$* \mathrm{p}<.10$.

$* * \mathrm{p}<.05$.

$* * * \mathrm{p}<0.01$. 
Figure A.1: Dynamic Effects of Occupational Recognition - Excluding Non-Applicants
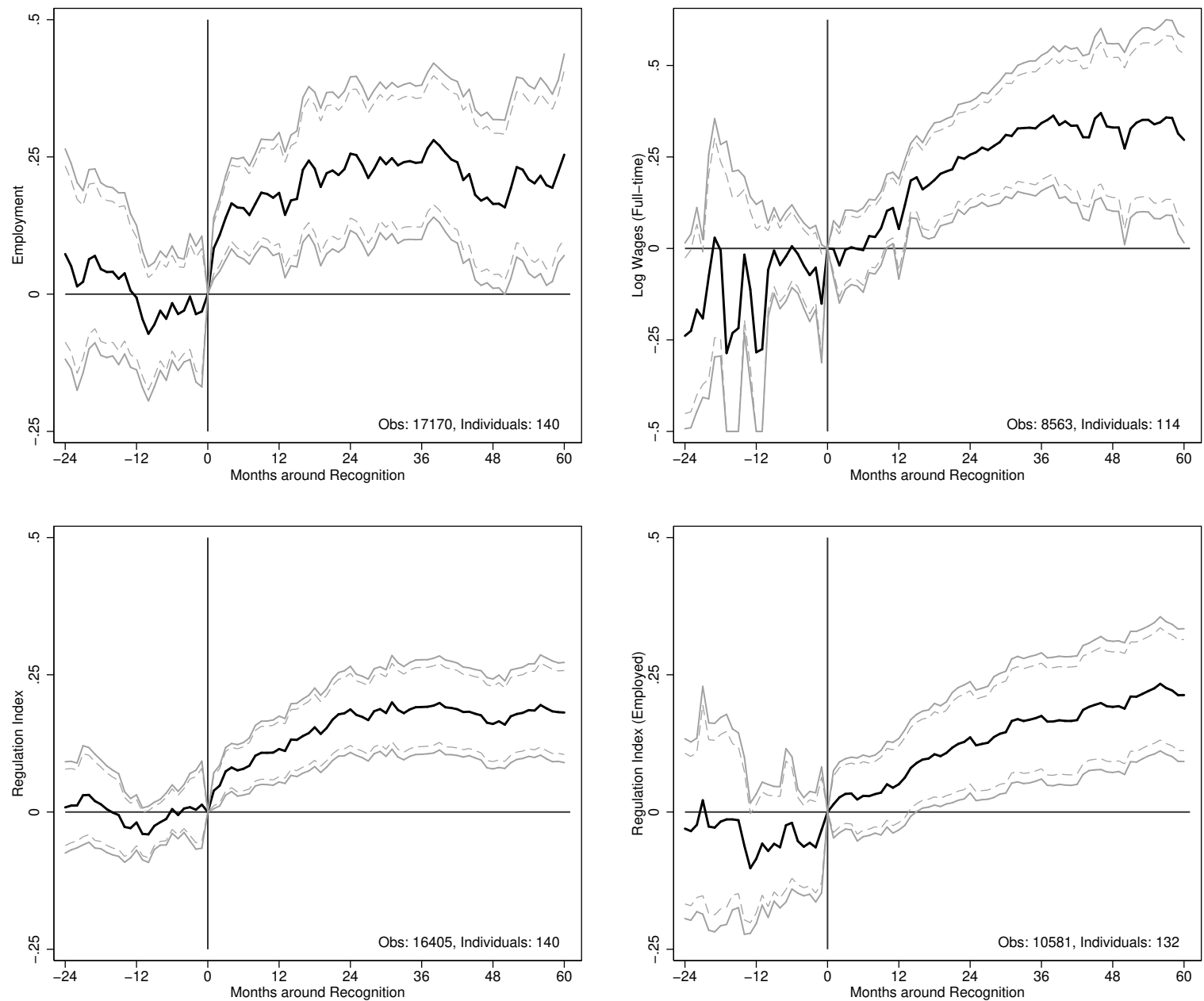

NOTE.-The figures report the coefficients of the period dummies obtained from estimating specification (2). The dependent variable is the share of days in employment per month (upper left panel), log real hourly wages for full-time employees averaged over all spells in a given month (upper right panel), the index of occupational regulation, assigning a value of zero to the non-employed (lower left panel) and the index of occupational regulation (lower right panel). Additional controls are the long-run average effect after recognition $\left(\operatorname{CertRecog}_{i, t-61}\right)$, the long-run average effect before recognition $\left(\operatorname{CertRecog}_{i, t+25}\right)$, an indicator variable for the application period, individual fixed effects, time fixed effects, time since migration fixed effects, age squared, and German language proficiency. The sample only comprises immigrants who eventually receive full recognition, and who migrated to Germany at the age of at least 18, stayed in Germany after arrival and do not have any reported incapacity for work. Observations are only included when migrant's age is at least 25 and less than $60.90 \%$ and $95 \%$ confidence intervals displayed using clustered standard errors at the individual level. Values of the confidence interval in the wage graph are cut at -0.5 for presentation purposes. 


\section{A.2 Selection into Record Linkage}

Table A.7: Descriptive Statistics by Consent to Record Linkage

\begin{tabular}{|c|c|c|c|}
\hline & No Consent (1) & Consent (2) & P-value (1)-(2) \\
\hline Male $(\%)$ & $\begin{array}{c}52.8 \\
(49.9)\end{array}$ & $\begin{array}{c}53.2 \\
(49.9)\end{array}$ & 0.82 \\
\hline Age & $\begin{array}{l}39.3 \\
(8.7)\end{array}$ & $\begin{array}{l}39.2 \\
(8.9)\end{array}$ & 0.80 \\
\hline No tertiary education (bef. migr.) (\%) & $\begin{array}{c}60.9 \\
(48.8)\end{array}$ & $\begin{array}{c}52.8 \\
(49.9)\end{array}$ & 0.00 \\
\hline Vocational (bef. migr.) (\%) & $\begin{array}{c}22.2 \\
(41.5)\end{array}$ & $\begin{array}{c}22.4 \\
(41.7)\end{array}$ & 0.83 \\
\hline University (bef. migr.) (\%) & $\begin{array}{c}17.0 \\
(37.6)\end{array}$ & $\begin{array}{c}24.8 \\
(43.2)\end{array}$ & 0.00 \\
\hline Proficiency in German (bef. migr.) & $\begin{array}{l}1.8 \\
(1.1)\end{array}$ & $\begin{array}{c}1.9 \\
(1.2)\end{array}$ & 0.03 \\
\hline Labor income (previous month) & $\begin{array}{c}1,891.3 \\
(1,373.8)\end{array}$ & $\begin{array}{c}1,993.7 \\
(1,527.9)\end{array}$ & 0.08 \\
\hline Net labor income (previous month) & $\begin{array}{l}1,341.5 \\
(862.7)\end{array}$ & $\begin{array}{l}1,393.9 \\
(943.5)\end{array}$ & 0.15 \\
\hline Employed (current) (\%) & $\begin{array}{c}56.8 \\
(49.5)\end{array}$ & $\begin{array}{c}64.6 \\
(47.8)\end{array}$ & 0.00 \\
\hline Marginal employment (current) (\%) & $\begin{array}{c}7.4 \\
(26.2)\end{array}$ & $\begin{array}{c}8.0 \\
(27.2)\end{array}$ & 0.47 \\
\hline Unemployed (current) (\%) & $\begin{array}{c}9.3 \\
(29.1)\end{array}$ & $\begin{array}{c}8.5 \\
(28.0)\end{array}$ & 0.39 \\
\hline Not in labor force (current) (\%) & $\begin{array}{c}26.5 \\
(44.1)\end{array}$ & $\begin{array}{c}18.8 \\
(39.1)\end{array}$ & 0.00 \\
\hline West \% & $\begin{array}{l}10.3 \\
(30.4)\end{array}$ & $\begin{array}{c}11.4 \\
(31.8)\end{array}$ & 0.24 \\
\hline East Europe (\%) & $\begin{array}{c}12.4 \\
(33.0)\end{array}$ & $\begin{array}{c}14.8 \\
(35.5)\end{array}$ & 0.03 \\
\hline South East Europe (\%) & $\begin{array}{c}22.6 \\
(41.9)\end{array}$ & $\begin{array}{c}21.8 \\
(41.3)\end{array}$ & 0.54 \\
\hline USSR (\%) & $\begin{array}{c}25.6 \\
(43.7)\end{array}$ & $\begin{array}{c}29.2 \\
(45.5)\end{array}$ & 0.01 \\
\hline Others $(\%)$ & $\begin{array}{c}29.0 \\
(45.4)\end{array}$ & $\begin{array}{c}22.8 \\
(42.0)\end{array}$ & 0.00 \\
\hline Observations & 1,891 & 2,085 & \\
\hline
\end{tabular}

NOTE.-Summary statistics based on IAB-SOEP Migration Sample. The table entries refer to the averages and standard deviations (in parentheses) of the characteristics listed in the first column. These statistics are obtained from the survey part of the IAB-SOEP Migration Sample, covering all first-generation immigrants aged between 25 and 59 with only one migration spell. "Proficiency in German" refers to the mean value of self-reported proficiency in reading, writing, and speaking, where the possible answers take value on a scale between 1 and 5 and correspond to: not at all, badly, okay, well, very well. "Current" refers to the time when the interview is taken, whereas "Previous Month" refers to the month prior to the interview.

The share of individuals who agree to the linkage of their survey responses to their administrative records across the three waves of the IAB-SOEP Migration Sample used in the empirical analysis is 52.4 percent. Table A.7 compares the average characteristics of individuals who gave their consent with those of individuals who did not, using the same sample selection criteria as in our main estimation sample (first-generation immigrants aged between 25 and 59 with only one migration spell). While similar in many dimensions, immigrants consenting to the record linkage are positively selected in terms of both their education and labor market performance.

To assess the importance of this type of selection for our estimation results, we follow 
Table A.8: Probability of Giving Consent to Record Linkage

\begin{tabular}{lc}
\hline Dependent Variable: Consent to Record Linkage & \\
\hline Age & $-0.015^{*}$ \\
& $(0.008)$ \\
Age sq. & $0.000^{*}$ \\
Female & $(0.000)$ \\
& 0.018 \\
Vocational (bef. migr.) & $(0.017)$ \\
& 0.014 \\
University (bef. migr.) & $(0.020)$ \\
& $0.113^{* * *}$ \\
Proficiency in German (bef. migr.) & $(0.020)$ \\
& 0.001 \\
Marginal employment (current) & $(0.007)$ \\
& -0.011 \\
Unemployed (current) & $(0.031)$ \\
& -0.039 \\
Not in fabor force (current) & $(0.028)$ \\
& $-0.105^{* * *}$ \\
East Europe & $(0.021)$ \\
South East Europe & 0.030 \\
& $(0.032)$ \\
USSR & -0.010 \\
Others & $(0.029)$ \\
& 0.020 \\
Individuals & $(0.029)$ \\
Pseudo R & -0.045 \\
Log Likelihood & $(0.029)$ \\
\hline
\end{tabular}

NOTE.-Table entries are the marginal effects from a probit regression where the dependent variable is an indicator for giving the consent to the record linkage. Education refers to completed education before moving to Germany. "Proficiency in German" is calculated as the mean value of self-reported proficiency in reading, writing, and speaking, where the possible answers take values on a scale between 1 and 5 and correspond to: not at all, badly, okay, well, very well. Excluded categories are: no tertiary education, employed, and Western countries. Standard errors in parentheses.

$* \mathrm{p}<.10$.

$* * \mathrm{p}<.05$.

$* * * \mathrm{p}<.01$.

an approach suggested by Lubotsky $(2007)^{1}$ who faces similar issues when linking SIPP and CPS survey data to US Social Security earnings records. In the first step, we run a probit model regressing an indicator for giving consent to the record linkage on the individuals characteristics listed in Table A.7. Table A.8 reports the corresponding marginal effects. $^{2}$ In the second step, we then use the inverse of the predicted probabilities from this probit model as weights in our main estimation. At least in terms of observable characteristics, this corrects for potential selection bias due to non-random matches between survey and administrative data. Since our vector of regressors includes the current

\footnotetext{
${ }^{1}$ Lubotsky, Darren. 2007. Chutes or ladders? A longitudinal analysis of immigrant earnings. Journal of Political Economy 115, no. 5:820-867.

${ }^{2}$ We do not include labor market income in the previous month as a regressor since that variable is missing for all non-employed individuals. If we do include it, we still obtain similar results despite the reduction in sample size.
} 
Table A.9: Main Results With Probability Weights Based on Table A.8

\begin{tabular}{|c|c|c|c|c|}
\hline & $\begin{array}{c}\text { Employment } \\
\text { (1) }\end{array}$ & $\begin{array}{c}\text { Log Wages } \\
\text { (Full-time) } \\
(2)\end{array}$ & $\begin{array}{l}\text { Regulation } \\
\text { Index } \\
(3)\end{array}$ & $\begin{array}{c}\text { Regulation Index } \\
\text { (Employed) } \\
(4)\end{array}$ \\
\hline \multicolumn{5}{|l|}{ Panel A: } \\
\hline Received full recognition & $\begin{array}{c}0.162^{* * *} \\
(0.050)\end{array}$ & $\begin{array}{c}0.160^{* *} \\
(0.080)\end{array}$ & $\begin{array}{c}0.155^{* * *} \\
(0.033)\end{array}$ & $\begin{array}{c}0.123^{* *} \\
(0.058)\end{array}$ \\
\hline \multicolumn{5}{|l|}{ Panel B: } \\
\hline Application period & $\begin{array}{c}0.019 \\
(0.065)\end{array}$ & $\begin{array}{l}-0.043 \\
(0.104)\end{array}$ & $\begin{array}{c}0.012 \\
(0.034)\end{array}$ & $\begin{array}{c}0.070 \\
(0.068)\end{array}$ \\
\hline Received full recognition & $\begin{array}{c}0.165^{* * *} \\
(0.052)\end{array}$ & $\begin{array}{c}0.148 \\
(0.103)\end{array}$ & $\begin{array}{c}0.157^{* * *} \\
(0.035)\end{array}$ & $\begin{array}{c}0.140^{* *} \\
(0.070)\end{array}$ \\
\hline Individuals with recognition & 140 & 114 & 140 & 132 \\
\hline Individuals without recognition & 1,077 & 715 & 1,077 & 948 \\
\hline Individuals total & 1,217 & 829 & 1,217 & 1,080 \\
\hline Observations & 136,053 & 50,952 & 129,218 & 73,977 \\
\hline
\end{tabular}

NOTE.-Panel A reports estimates based on specification (1), Panel B adds an indicator variable for the application period as discussed in the text. The dependent variable is the share of days in employment per month in column (1), log real hourly wages for full-time employees averaged over all spells in a given month in column (2), the index of occupational regulation, assigning a value of zero to the non-employed, in column (3), and the index of occupational regulation in column (4). Additional controls are individual fixed effects, time fixed effects, time since migration fixed effects, age squared, and German language proficiency. Observations are weighted by the inverse probability of agreeing to the linkage with the social security records, computed from the probit results reported in Table A.8. Standard errors in parentheses are clustered at the individual level.

$* \mathrm{p}<.10$.

$* * \mathrm{p}<.05$.

$* * * \mathrm{p}<.01$

employment status, it should to some extent also capture unobservable factors such as a worker's motivation or ability. Table A.9 and Figure A.2 show the static and dynamic results based on the weighted regressions which are similar to our baseline results reported in Table 3 and Figure 1. 
Figure A.2: Dynamic Effects With Probability Weights Based on Table A.8
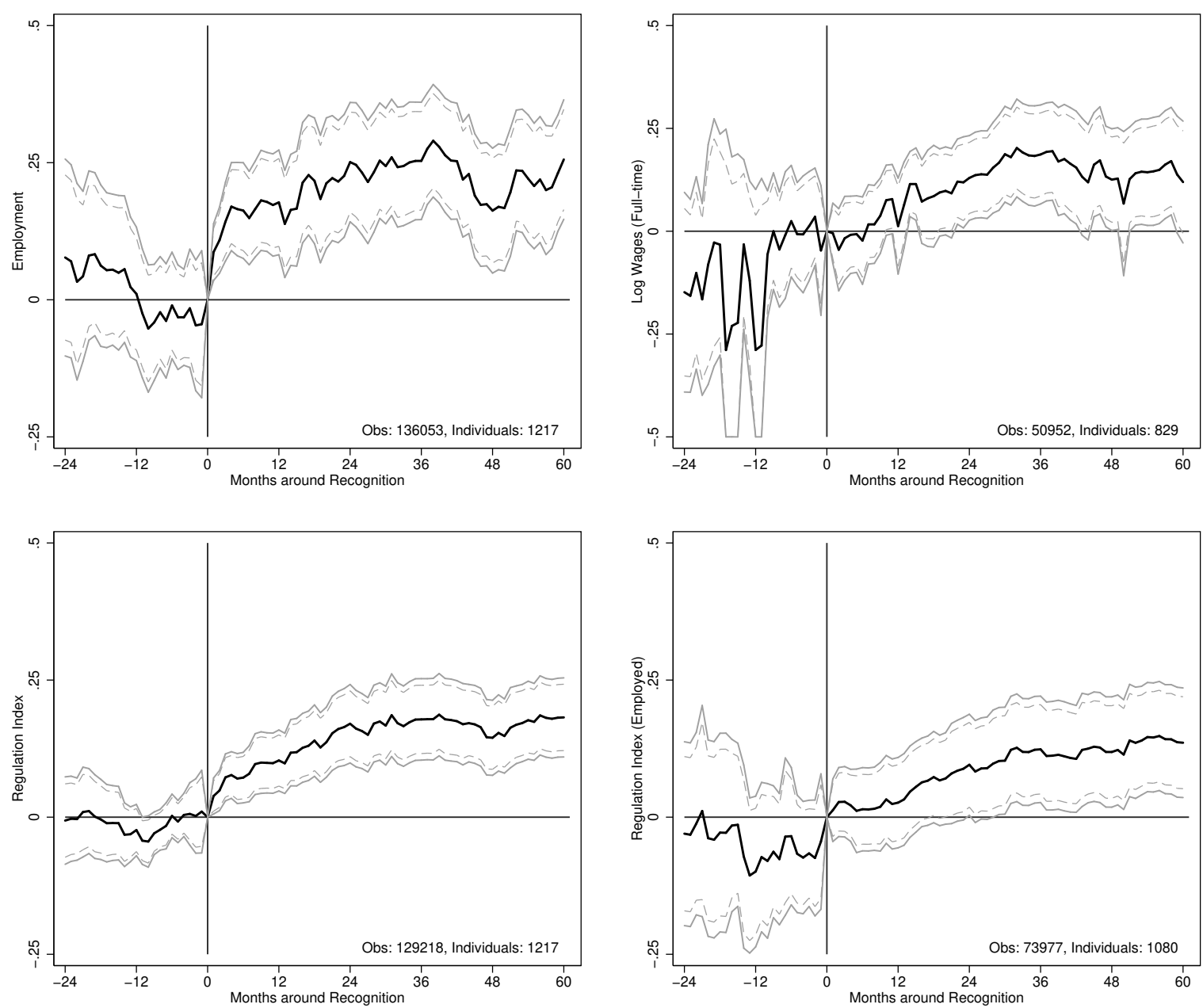

NOTE.-The figures report the coefficients of the period dummies obtained from estimating specification (2). The dependent variable is the share of days in employment per month (upper left panel), log real hourly wages for fulltime employees averaged over all spells in a given month (upper right panel), the index of occupational regulation, assigning a value of zero to the non-employed (lower left panel) and the index of occupational regulation (lower right panel). Additional controls are the long-run average effect after recognition $\left(\operatorname{CertRecog}_{i, t-61}\right)$, the long-run average effect before recognition $\left(\operatorname{CertRe} \operatorname{cog}_{i, t+25}\right)$, an indicator variable for the application period, individual fixed effects, time fixed effects, time since migration fixed effects, age squared and language proficiency. Observations are weighted by the inverse probability of agreeing to the linkage with the social security records, computed from the probit results reported in Table A.8. 90\% and 95\% confidence intervals displayed using clustered standard errors at the individual level. Values of the confidence interval in the wage graph are cut at -0.5 for presentation purposes. 


\section{A.3 Synthetic Control Method}

Figure A.3: Dynamic Employment Effects of Occupational Recognition
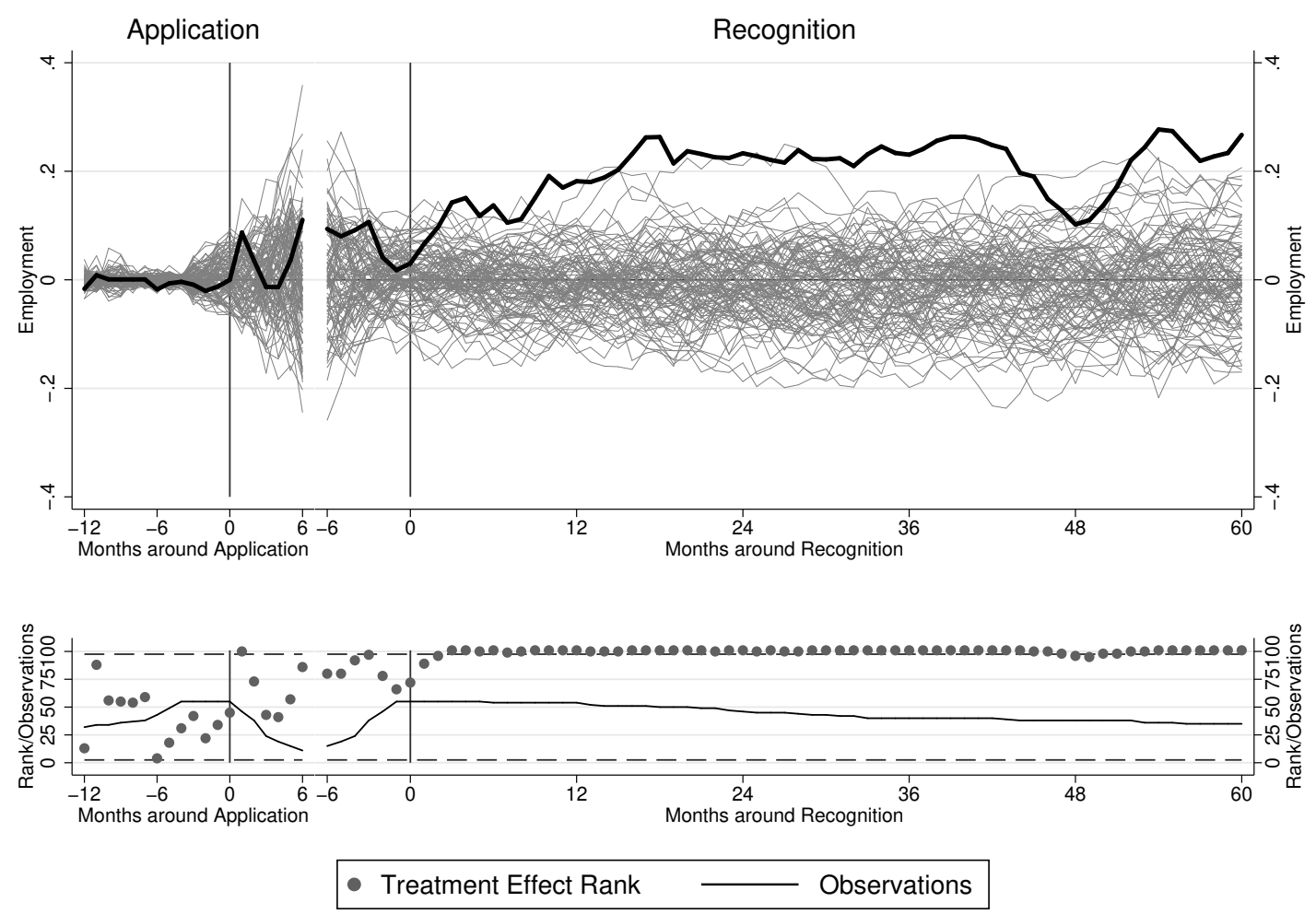

NOTE.-The displayed estimates along the thick black lines are the average differentials in employment in each pre- and post-treatment period between all treated units and their synthetic control groups. The thin gray lines depict 100 placebo estimations, in which we iteratively apply the synthetic control method to randomly selected non-treated immigrants in each treated immigrant's donor pool.

As a robustness check for our dynamic estimation, we apply a pooled version of the synthetic control method proposed by Abadie et al. (2010). In contrast to our main approach, each immigrant who receives recognition (the treatment) is here matched to a set of other immigrants who never applied for recognition but whose labor market outcomes in the period prior to application are similar to those of the treated immigrant. We obtain a synthetic control group for each treated immigrant and then average the dynamic treatment effects in each pre- and post-treatment month across all treated individuals in the sample in those months. Note that we match directly on the corresponding outcome variables in the year prior to application, excluding the last three months to test for anticipation effects.

The thick black lines in Figures A.3 and A.4 show the resulting dynamic impacts of occupational recognition on employment and hourly wages between 12 months before the application period and 60 months after recognition. We consider hourly wages rather than log hourly wages since otherwise it would be difficult to find potential control individuals with positive wages in precisely the same months as the treated individuals. This 
Figure A.4: Dynamic Wage Effects of Occupational Recognition
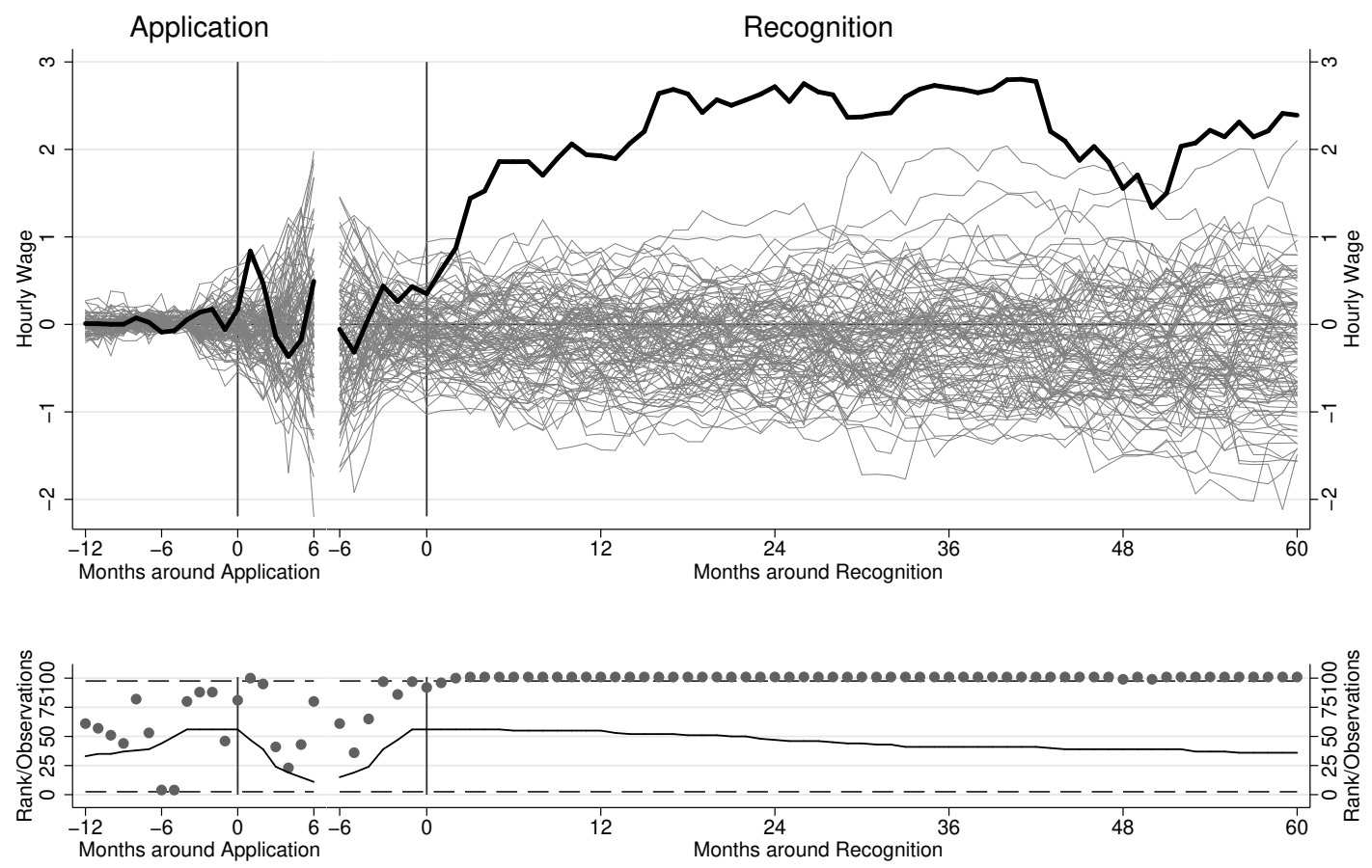

- Treatment Effect Rank Observations

NOTE.-The displayed estimates along the thick black lines are the average differentials in hourly wages in each preand post-treatment period between all treated units and their synthetic control groups, including zeros for non-employed individuals. The thin gray lines depict 100 placebo estimations, in which we iteratively apply the synthetic control method to randomly selected non-treated immigrants in each treated immigrant's donor pool.

implies that part of the estimated impacts on hourly wages are driven by individuals finding employment and starting to earn non-zero wages. Overall, the dynamic patterns are similar to those obtained from our regression-based approach, with substantial and relatively quick increases in both employment and hourly wages in the months immediately after recognition, continuing divergence at a slower pace for a couple of years, and a flattening out of the two profiles thereafter.

To assess the statistical significance of the dynamic effects from the synthetic control group method, we perform 100 placebo estimations in which, for each iteration, we randomly pick for each treated immigrant an untreated immigrant from his or her donor pool, assign the same hypothetical application and recognition dates as for the treated immigrant, find a suitable synthetic control group for this placebo immigrant, and then aggregate all dynamic impact estimates across all placebo immigrants. As illustrated by the thin gray lines in Figures A.3 and A.4, the estimated effects of actual occupational recognition are large relative to the distribution of dynamic placebo effects, suggesting that they pick up real employment and wage effects. Contrary to the regression-based results reported in Table 3, we find some indication for a significant positive effect of 
Figure A.5: Dynamic Effects of Occupational Recognition on the Degree of Regulation
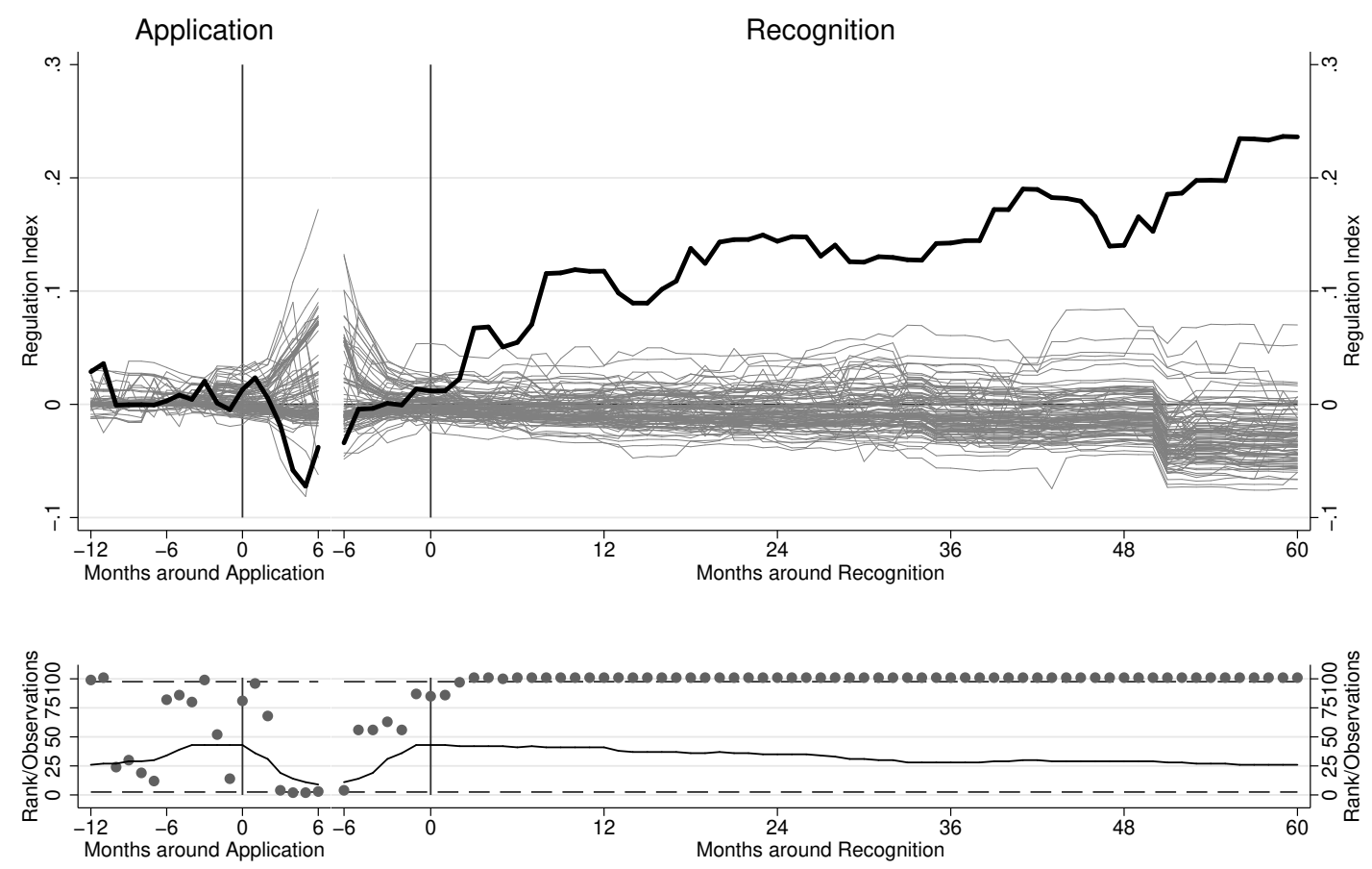

- Treatment Effect Rank — Observations

NOTE.-The displayed estimates along the thick black lines are the average differentials in the regulation index in each preand post-treatment period between all treated units and their synthetic control groups, including zeros for non-employed individuals. The thin gray lines depict 100 placebo estimations, in which we iteratively apply the synthetic control method to randomly selected non-treated immigrants in each treated immigrant's donor pool.

applying itself on the probability of being employed although this effect only extends to the first month after submitting the application.

To facilitate the assessment of the statistical significance of the estimated treatment effects in each period, we depict their rank among the distribution of placebo effects (gray dots) and the underlying number of treated individuals (black line) for each period in a separate plot underneath the main graphs. Note that the sample size of treated individuals used in these estimations is substantially smaller than in our main approach since we need to condition on observing individuals for at least one period prior to their application and for at least one period between their application and their recognition date. Individuals who apply in the month they are first observed in the IEB data or individuals who obtain the result of their application in the same month in which they apply are thus excluded from the estimation sample.

Figure A.5 displays the corresponding dynamic effects for the average occupational regulation index, where the index is set to zero for non-employed individuals as in our main approach without conditioning on employment. The latter is not feasible under the synthetic control approach as it would require finding suitable control individuals with 
exactly the same monthly employment histories as the treated individuals. Similar to the pattern documented in the bottom left panel of Figure 1, there is a swift increase in the regulation index after obtaining full recognition which continues more or less uninterruptedly throughout the entire post-recognition period, amounting to a value of almost 0.25 after five years.

Overall, while not exactly comparable in terms of the outcome variables considered, we view the evidence from the synthetic control method as supportive of the main findings from our regression-based difference-in-differences approach, indicating significant and quantitatively large effects of occupational recognition on immigrants' labor market outcomes. 